Board of Governors of the Federal Reserve System

International Finance Discussion Papers

Number 548

April 1996

\title{
THE SYNDROME OF EXCHANGE-RATE-BASED STABILIZATIONS AND THE UNCERTAIN DURATION OF CURRENCY PEGS
}

Enrique G. Mendoza and Martín Uribe

Note: International Finance Discussion Papers are preliminary materials circulated to stimulate discussion and critical comment. References in publications to International Finance Discussion Pupers (other than an acknowledgment that the writer had access to unpublished material) should be cleared with the author or authors. 


\begin{abstract}
This paper conducts a quantitative examination of the hypothesis that uncertain duration of currency pegs causes the sharp real appreciations and business cycles that affect chronically countries using fixed exchange rates as an instrument to stop high inflation. Numerical solutions of equilibrium dynamics of a two-sector small open economy with incomplete markets show that uncertain duration rationalizes the syndrome of exchange-rate-based stabilizations without price or wage rigidities. Three elements of the model are critical for these results: (a) a strictly-convex hazard rate function describing time-dependent devaluation probabilities, (b) the wealth effects introduced by incomplete insurance markets, and (c) the supply-side effects introduced via capital accumulation and elastic labor supply. Uncertain duration also entails large welfare costs, compared to the perfect-foresight credibility framework, although temporary disinflations are welfare-improving. The model's potential empirical relevance is examined further by reviewing México's post-war experience with the collapse of six currency pegs.
\end{abstract}




\title{
The Syndrome of Exchange-Rate-Based Stabilizations and the Uncertain Duration of Currency Pegs
}

\author{
Enrique G. Mendoza and Martín Uribe
}

\section{Introduction}

The chronic economic crises and currency collapses that affect developing economies, dramatically exemplified by the collapse of the Mexican peso in December of 1994, are one of the most widely studied issues in international macroeconomics. One key question that research in this area has aimed to answer is: why do disinflation programs based on fixed exchange rates set in motion a perverse dynamic process that often leads to the breakdown of the program itself? In the Mexican case, for example. a stabilization plan that practically fixed the peso-dollar exchange rate, and successfully tightened fiscal and monetary policies, had been in place for seven years prior to the collapse. During this period, the real exchange rate appreciated sharply, investment and consumption boomed, and external imbalances widened markedly. These three phenomena define the syndrome of exchange-ratebased stabilizations (ERBS) documented extensively in international studies by Kiguel and Liviatan (1992) and Végh (1992)), and observed in the five previous attempts at fixing the exchange rate undertaken in México since 1945.2

Early studies by Dornbusch (1982) and Rodriguez (1982), based on adaptive expectations and sticky prices, attribute ERBS syndrome to inflationary inertia. A fixed exchange rate causes a boom in domestic absorption because it lowers the real interest rate, as interest parity forces the nominal interest rate to fall and inflationary expectations adjust slowly. Persistent inflation combined with the currency peg produces the real appreciation. A different approach based on two-sector intertemporal equilibrium

'We thank David Bowman, Guillermo Calvo, Allan Drazen, Sebastian Edwards, Jon Faust, Graciela Kamirisky, John Rogers, and seminar participants at Banco de México, the Federal Reserve Boar ine Wharton School of Business, and the Winter 1996 Meetings of the Society for Economic Dynamics and Control for helpful comments and suggestions. This paper reflects only the authors' views and not those of the Board of Governors of the Federal Reserve System or other members of its staff.

${ }^{2}$ México's long post-war experience with fixed-exchange-rates is examined in Section 4. Gomez-Oliver (1981) and Aspe (1993) also review post-war Mexican currency crises. 
models, as those developed by Dornbusch (1983) and Greenwood (1984), suggests that real appreciation and large external deficits can be features of transitional dynamics induced by sustained stabilization and structural reforms (as in Uribe (1995) and Roldós (1995)). Equilibrium models that examine the consistency between fiscal and exchange-rate policies by Helpman and Razin (1987) and Drazen and Helpman (1988) provide a third explanation for the real effects of disinflation. This literature emphasizes wealth effects resulting from the timing of expected cuts in the inflation tax and government expenditures.

Calvo (1986) proposed an alternative view in which ERBS syndrome results from the lack of credibility in government policies. Policies lack credibility because of chronic failures of stabilization plans and mishandling of financial policies. Broadly defined, the credibility problem, also known as the temporariness hypothesis, refers to a situation in which a policy is implemented, but agents question whether it can be maintained. For example, in Calvo's model agents expect the collapse of a fixedexchange-rate regime at a future date, and this acts like a temporary tax on savings, which, via intertemporal substitution, rationalizes ERBS syndrome. Thus, this setup shares with the price-inertia approach the view that the syndrome is a warning signal suggesting that a currency peg is unsustainable, but with the key differences that (a) real appreciation is an endogenous outcome, rather than the exogenous trigger of the crisis, and (b) economic policies are part of the problem rather than the solution.

Several studies have examined the empirical relevance of the Dornbusch-Rodriguez model and the equilibrium models (see for example Edwards (1993) and (1996), Fernandez (1985), and Mendoza (1995)). While the models help to explain the experience of countries where price inertia or structural change were important, the experience of countries where, as in México in 1994, crisis emerged despite the dismantling of indexation mechanisms and rapid structural change remains a puzzle. Similarly, lack of consistent fiscal adjustment during a currency peg was relevant in explaining the collapse of the disinflation programs examined by Helpman and Razin (1987), but is less relevant for explaining the Mexican crash and the Argentinean recession of 1994-95, since these countries tightened fiscal policy 
considerably. The objective of this paper is to examine whether the credibility hypothesis can help to explain these puzzles.

Despite significant developments in the theory of credibility, little is still known about its quantitative implications. Early studies addressing this issue by Reinhart and Végh $(1994,1995)$ simulated perfect-foresight models, in which it is known that a policy change announced at date $t$ will be reversed at some date $\mathrm{t}+\mathrm{j}$. These studies highlighted flaws of the basic credibility model, thus justifying extensions adding price stickiness and supply-side effects via labor supply and capital accumulation (see Lahiri (1995), Rebelo and Végh (1995), Roldós (1995), and Uribe (1995)). However, empirical research in this area was challenged by recent theoretical studies showing that perfect-foresight models are inadequate for assessing the relevance of lack of credibility because of the probabilistic nature of the credibility problem. In practice, agents do not know the date in which a stabilization plan will fail, but only attach a certain probability to that event. Thus, the credibility problem is really a problem of "uncertain duration" of a policy regime, as in Drazen and Helpman (1988) and Calvo and Drazen (1993).

Uncertain duration is a key distinction because it alters the qualitative predictions of perfectforesight credibility models, and hence it affects their quantitative assessment. Calvo and Drazen (1993) showed that, ruling out risk-neutrality, the predictions of perfect-foresight models extend to uncertainduration models only if insurance markets are complete. They examined a small open, endowment economy where the government abolishes tariffs but agents attach some probability to their reinstatement. Under complete markets, the results of the perfect-foresight analysis of Calvo (1988) are reproduced: consumption jumps when the tariff is cut, and remains constant until it collapses when the trade reform fails (Figure 1a).

The assumption of complete markets is at odds with the reality of countries considered candidates for the credibility problem, ${ }^{3}$ and hence it is not surprising that several features of economir fluctuations in these countries challenge the predictions of complete-markets, or perfect-foresight,

\footnotetext{
${ }^{3}$ Calvo and Mendoza (1996) review massive runs on public debt that played a key role in the Mexican crisis.
} 
credibility models. In particular, economic booms, widening external imbalances, and real appreciations do not occur in discrete jumps, and they are significantly larger than what can be accounted for by the intertemporal substitution channel emphasized under complete markets. Rebelo and Végh (1995) showed that frictions on preferences and technology can help produce gradual consumption booms, but even then investment and money balances adjust in discrete jumps. Moreover, the perfect-foresight model is far from explaining the size of the observed boom-recession cycles, unless it is augmented by exogenous inflation stickiness. The latter, however, leaves the large real appreciations unexplained and weakens the case for the credibility hypothesis.

In the more realistic case that insurance markets are incomplete, Calvo and Drazen (1993) showed that uncertain duration produces outcomes that differ markedly from perfect-foresight outcomes, depending on the strength of income effects introduced by market incompleteness relative to intertemporal substitution effects. The former depend in turn on the size of tariff revenue rebates and on the households' degree of risk aversion (or the reciprocal of the intertemporal elasticity of substitution in the classic setup with isoelastic, time-separable utility). If tariff revenue is fully rebated, consumption rises on impact when the tariff is reduced, and then falls gradually until it collapses when the tariff is increased again (Figure 1b). The same occurs if tariff revenue is not rebated and the coefficient of relative risk aversion (CRRA) is less than 1 . If tariff revenue is not rebated and CRRA $>1$, there is a gradual boom for the duration of the tariff cut (Figure lc). Thus, uncertain duration explains qualitatively the gradual booms and real appreciations observed in the data. However, whether the quantitative predictions of the model are also consistent with the data is still unknown. Moreover, Calvo and Drazen (1993) examined only demand-driven uncertain-duration effects, and thus the implications of uncertain duration in a general equilibrium setting are still unexplored.

This paper extends theoretical work on uncertain duration to examine the quantitative implications of a model in which lack of credibility is modelled as the probability of abandonment of a currency peg. The model describes the general equilibrium of a small open economy with the features of 
production, labor supply, and capital and debt accumulation examined in the credibility literature and in international real business cycle $(\mathrm{RBC})$ theory. Insurance markets are incomplete and money enters through a transactions-costs technology. The model's equilibrium stochastic processes are simulated numerically using a recursive, near-exact-solution method given an exogenous hazard function governing the probability of devaluation.

The introduction of uncertain duration in this manner links credibility models to empirical work on balance-of-payments crises. This is accomplished by calibrating the model to mimic the probabilities of devaluation under fixed exchange rates estimated by Blanco and Garber (1986), Goldberg (1994), and Klein and Marion (1994). These studies show that devaluation probabilities are "J-shaped," so that currency pegs are expected to fail with more probability near the dates of introduction and abandonment than in the period in between. Thus, we ask the question: if the probability of devaluation is set to estimates derived from the data, are equilibrium allocations produced by an uncertain duration model consistent with the stylized facts?

Simulation results suggest that uncertain duration is sufficient to cause economic fluctuations and real appreciations similar to those attributed to ERBS syndrome. Moreover, the patterns of booms followed by recessions, with the latter starting in some cases prior to the currency crisis, and the existence of periods of real-exchange-rate stability in between sharp appreciations, are also replicated by the model. These results follow from comparing the simulations with the stylized facts identified in the empirical literature on ERBS syndrome, and from a case study based on the six failed currency pegs implemented in México since 1945.

The wealth effects associated with seignorage and transaction costs under incomplete markets, the supply-side effects introduced by the general-equilibrium nature of the model, and the "J-shaped" hazard rate function defining devaluation probabilities, are critical for the favorable results of the simulations. These elements of the model also imply that the welfare costs of uncertain duration largely exceed the trivial costs of lack of credibility obtained in perfect-foresight studies (see Calvo (1988)). In 
contrast with these studies, stabilizations of uncertain duration improve welfare, starting from a highinflation equilibrium. Uncertain duration is costly in the sense that it absorbs a large fraction of the benefits of a fully-credible disinflation.

The rest of the paper is organized as follows. Section 2 describes the model, and discusses simulation issues. Section 3 presents the quantitative analysis and examines policy implications. Section 4 compares Mexican data to the model's predictions. Section 5 concludes.

\section{Uncertain Duration of a Currency Peg in a SmaH Open Economy}

Preferences, Technology, and Financial Markets

Households maximize expected lifetime utility, which takes the conventional isoelastic form:

$$
\begin{gathered}
E_{0} \sum_{t=0} \frac{\left[\left[\omega\left(C_{t}{ }^{T}\right)^{-\mu}+(1-\omega)\left(C_{t}^{N}\right)^{\mu}\right]^{\frac{1}{\mu}}\left(1-L_{t}{ }^{N}-L^{T}\right)^{T}\right]^{1-\sigma}}{1-\sigma} \\
C\left(C_{t}{ }^{T}, C_{t}{ }^{N}\right)=\left[\omega\left(C_{t}{ }^{T}\right)^{-\mu}+(1-\omega)\left(C_{t}{ }^{N}\right)^{-\mu}\right]^{\frac{1}{\mu}}
\end{gathered}
$$

Households are infinitely-lived and consume a traded good $\left(C_{t}^{T}\right)$ and a nontraded good $\left(C_{t}^{M}\right)$. They supply labor inelastically to the industry that produces traded goods, in the amount $L^{r}$, and trade off the remaining "time supply" between providing labor to the nontraded goods industry $\left(L_{t}^{M}\right)$ or enjoying leisure $\left(\ell_{t}\right)$. The total time constraint is $\ell_{t}=1-L_{t}^{N}-L^{T}$. The expectations operator $E_{o}$ applies to the probability of duration of a currency peg, as defined below. Preferences between $C^{T}$ and $C^{N}$ are represented by a constant-elasticity-of-substitution (CES) function, where $1 / 1+\mu$ is the elasticity of substitution between traded and nontraded goods, and $\omega$ is the share of traded goods in consumption of the aggregate $C$, defined by the CES composite good in equation (2). Leisure is modelled in multiplicative form in the momentary utility function, with $p$ governing the elasticity of substitutiol ir. labor supply. Utility from $C$ and $\ell$ is represented also by an isoelastic function, where $1 / \sigma$ is the intertemporal elasticity of substitution. $\beta$ is the discount factor. 

capital:

Households maximize (1) subject to the following budget constraint and law of motion for

$$
\begin{aligned}
& B_{t \cdot 1}-(1+r \cdot) B_{t}+\left(C_{t}{ }^{T}+p_{t}^{N} C_{t}^{N}\right)+I_{t}= \\
& A_{t}{ }^{T}\left(K_{t}{ }^{T}\right)^{1-\alpha T}\left(L^{T}\right)^{\approx T} \cdot p_{t}^{N} A_{t}^{N}\left(K^{N}\right)^{1-\alpha N}\left(L_{t}{ }^{N}\right)^{\alpha N}-\frac{\phi}{2}\left(K_{t-1}^{T}-K_{t}{ }^{T}\right)^{2}-m_{t} V S(V)+\frac{m_{t-1}}{1+e_{t}}-m_{t} T_{t} \\
& I_{t}=K_{t .1}^{T}-(1-8) K_{t}^{T}
\end{aligned}
$$

The budget constraint (3) has implicit the characterization of production technologies and financial markets of the model. International financial markets are incomplete. In particular, world asset trading is limited to one-period bonds $B$ paying the time-invariant rate $r^{*}$ in units of the traded good. Uses of household income in the left-hand-side of (3) include private absorption (i.e. purchases of traded and nontraded goods for consumption and investment, with $p^{N}$ defining the relative price of nontradables or the real exchange rate) and changes in bond holdings net of interest (which finance the current account).

The sources of household income in the right-hand-side of (3) include capital and labor income from industries producing traded and nontraded goods, net of capital-adjustment costs, transaction costs, changes in real money balances, and net transfers from government. Production technologies are CobbDouglas, with capital inelastically supplied to the nontraded sector at the level $K^{N}$, assuming that $K^{N}$ has a zero depreciation rate. ${ }^{4} K^{T}$ is assumed to be a traded good. Traded- and nontraded-sector industries are perfectly competitive, so production is exhausted in paying factor incomes--hence production functions enter into the households' budget constraint without loss of generality. Capital-adjustment costs distinguish financial assets from physical assets to prevent excessive investment variability (see Mendoza (1995)).

Real money balances $m$ enter the model as a means to economize transaction costs. Following Greenwood (1983), transactions costs per unit of private absorption are given by $S$, which is a convex

\footnotetext{
${ }^{4}$ Mendoza (1995) and Rebelo and Végh (1995) assume similar production environments in which labor (capital) is inelastically supplied in the traded (nontraded) sector.
} 
function of expenditure velocity $V=\left(C^{T}+p^{N} C^{N}+I\right) / m$. Thus, $m V S(V)$ represents total transaction costs. Real money balances carried over from earlier periods depreciates at the rate $e$. If PPP in tradable goods holds and foreign prices are constant, $e$ represents both the inflation and the depreciation rates.

$T$ is a lump-sum transfer from the government. The government issues money and uses $T$ to rebate to households fractions $\eta_{m}$ and $\eta_{S}$ of seignorage and transaction costs; $\eta_{m}=\eta_{S}=0$ is a case in which revenue finances unproductive expenditures $G .^{5}$ The government budget constraints are:

$$
\begin{gathered}
G_{t}+T_{t}=m_{t}-\frac{m_{t-1}}{1+e_{t}}+m_{t} V_{t} S(V t) \\
T_{t}=\eta_{m}\left(m_{t}-\frac{m_{t-1}}{1+e_{t}}\right) \cdot \eta_{S}\left(m_{t} V S(V)\right), \quad 0 \leq \eta_{m}, \eta_{S} \leq 1
\end{gathered}
$$

The policy experiment referred to as a currency peg of uncertain duration is the following. At $t=0$ the government announces and implements the policy $e_{o}=0$. Agents attach a time-dependent, conditional probability $z_{t}=\operatorname{Pr}\left[e_{t+1}>0 \mid e_{1}=0\right]$, defined by the hazard rate function $Z(t)$, to the abandonment of the peg. As in Calvo and Drazen (1993), the abandonment of the peg is an absorbent state, so if at any date $t>0$ the rate of devaluation is positive, it is assumed to remain positive forever with full certainty $\left(\operatorname{Pr}\left[e_{t+1}>0 \mid e_{t}>0\right]=1\right)$.

Equilibrium and Numerical Solution Method

The first-order conditions of the households' optimization problem are the following:

$$
\begin{gathered}
\lambda_{t}=\frac{\omega}{1+S\left(V_{t}\right)+V S^{\prime}\left(V_{t}\right)}\left(\frac{C_{t}^{T}}{C_{t}}\right)^{-(1 \cdot \mu)} C_{t}^{-\sigma}\left(1-L_{t}^{N}-L{ }^{T}\right)^{p(1-\sigma)} \\
p_{t}^{N}=\frac{1-\omega}{\omega}\left(\frac{C_{t}^{N}}{C_{t}^{T}}\right)^{-(1-\mu)}
\end{gathered}
$$

${ }^{5}$ Under full rebates, the assumption that transaction costs are rebated to households by government can also be interpreted as assuming that households own the banking system and they collect its net profits. 


$$
\begin{aligned}
& C_{t}^{1-\sigma} \rho\left(1-L_{t}^{N}-L^{T}\right)^{(\rho(1-\sigma)-1)}=\lambda_{t} \alpha N A_{t}^{N}\left(\frac{K^{N}}{L_{t}^{N}}\right)^{1-\alpha N} p_{t}^{N} \\
& \lambda_{1}=\beta E_{t} \lambda, \ldots 1(1+r *) \\
& \lambda_{1}\left[1-S^{\prime}\left(V_{t}\right) V_{t}^{2}\right]-\beta E_{t} \frac{\lambda_{t \cdot 1}}{1+e_{t \cdot 1}} \\
& \lambda_{d}\left[1+S\left(V_{t}\right)+V S^{\prime}\left(V_{t}\right)+\phi\left(K_{t \cdot 1}^{T}-K_{t}^{T}\right)\right]- \\
& \beta E_{t} \lambda, \ldots\left[(1-\alpha T) A_{t, 1}^{T}\left(\frac{K_{t, 1}^{T}}{L_{t, 1}^{T}}\right)^{-\alpha T}+(1-\delta)\left(1+S\left(V_{t, 1}\right)+V_{t, 1} S^{\prime}\left(V_{t, 1}\right)\right)+\phi\left(K_{t, 2}^{T}-K_{t, 1}^{T}\right)\right]
\end{aligned}
$$

Equation (7) is the marginal utility of wealth, using $C^{T}$ as the numeraire. Equation (8) reflects optimal sectoral allocation of consumer demand by equating the marginal rate of substitution between $C^{T}$ and $C^{N}$ to the corresponding relative price. Equation (9) reflects the optimal leisure-consumption decision by equating the marginal disutility of labor in the nontradables sector to its marginal product. It follows from (8) and (9) that the real exchange rate in this model is driven by supply and demand effects, in contrast with the conventional Balassa-Samuelson model in which perfect sectoral labor mobility implies that $p^{n}$ is supply-determined by the ratio of sectoral labor productivities. Equations (10)-(12) are standard Euler equations that equate the marginal costs and benefits of accumulating foreign assets, real balances, and physical capital.

Equation (11) is crucial for understanding the intertemporal substitution effects triggered by uncertain duration. Define $\lambda^{H}$ and $\lambda^{L}$ as the marginal utility of $C^{T}$ under equilibrium allocations for high and low inflation respectively. It follows that (11) can be rewritten as: 


$$
\lambda_{t}^{L}\left[1-S^{\prime}\left(V_{t}^{L}\right)\left(V_{t}^{L}\right)^{2}\right]=\beta\left[z_{t} \frac{\lambda_{t \cdot 1}^{H}}{1+e_{t, 1}}+\left(1-z_{t}\right) \lambda_{t, 1}^{L}\right]
$$

It is clear from (13) that the devaluation rate $e_{t+l}$ is a tax on real balances carried over from the past. The probability of devaluation $z_{\imath}$ plays a very similar role. A higher $z_{t}$ increases the effective tax rate on real balances by attaching a higher probability to the devaluation scenario. Thus, uncertain duration can be interpreted as a case of random taxation, which explains why credibility and policy temporariness are treated as synonymous. Note, however, that under uncertain duration the probability of reversal of the policy $\left(z_{l}\right)$ is separated from the policy instrument $\left(e_{t+1}\right)$ itself.

Through the transaction costs technology, the distortions induced by uncertain duration on real balances are transmitted into the real sector of the economy. If seignorage and transaction costs are fully rebated, the distortions are limited to intertemporal substitution effects. ${ }^{6}$ Under complete markets the experiment reduces to a fully anticipated price increase. Consumption is temporarily higher at a constant level in the low-price period, and collapses to a lower constant level in the high-price period. Under incomplete markets, in contrast, a long-lasting currency peg represents a sequence of favorable relative price shocks with non-insurable income effects. These effects are magnified if seignorage and transaction costs are not rebated. Each quarter that a peg survives induces a positive shock to permanent income, which rises by the amount of seignorage and transaction costs that would have been collected under high inflation. The impact on economic dynamics resulting from all these effects depends critically on the shape of the hazard rate function, as we show later.

In equilibrium, conditions (7)-(12) hold jointly with market-clearing conditions:

$$
C_{t}^{N}=A_{t}^{N}\left(K^{N}\right)^{1-\alpha N}\left(L_{t}^{N}\right)^{\alpha N}
$$

\footnotetext{
${ }^{6}$ Note that equations (9) and (12) introduce the so-called supply-side effects (see Roldós (1995), Lahiri (1995), and Uribe (1995)), via the capital accumulation and leisure-consumption choices.
} 


$$
C_{t}^{T} \cdot G_{t} \cdot I_{t} \cdot B_{t \cdot 1}-B_{t}(1+r \cdot) \cdot A_{t}^{T}\left(K_{t}^{T}\right)^{1-\varangle T}\left(L^{T}\right)^{\star \top T}-\frac{\Phi}{2}\left(K_{t \cdot 1}^{T}-K_{t}^{T}\right)^{2}
$$

The equilibrium stochastic processes of the model are given by sequences of state-contingent allocations and prices such that (7)-(12) and (14)-(15) hold for $t=0, \ldots \infty$. Since at any date $t>0$ there are two possible realizations of $e$, and since the state $e_{t}>0$ is absorbent, in each date macroeconomic aggregates can either: (a) follow the optimal path corresponding to the state in which $e_{t}=0$ at $t$, with $z_{t}$ governing the probability that $e_{t+1}>0$, or (b) if $e_{t}>0$ at $t$ they switch to the path corresponding to that rate of devaluation with perfect-foresight. The benchmark version of the model is solved by assuming that at some future date $J$ the currency collapses with probability 1 , so that $z_{J-1}=1$, and by specifying exogenously a function $Z$ to determine $z_{1}$ for $t=0, \ldots, J-2$. This provides well-defined state-transition probabilities and terminal conditions, so that paths (a) and (b) can be solved by backward-recursion following the intuition from the two-period analysis in Calvo and Mendoza (1994). The multi-period analysis has the complication that the net foreign asset position set as terminal condition at the time of the collapse must be consistent with the initial net foreign asset position at the time the currency peg starts. This is achieved by constructing a shooting routine which undertakes successive iterations on the terminal conditions. Details are provided in the Appendix.

The benchmark version of the model is parameterized for a quarterly frequency as follows. a) Financial Sector: The transaction costs technology adopts the form $S(V)=A V_{t}^{\gamma}$, so that the first-order conditions imply an implicit money demand function $V_{1}=(i / 1+i)^{1 /(1+\gamma)}(\gamma A)^{-1 /(1+\gamma)}$, where $i$ is the nominal interest rate. This function is calibrated to M2 money demand in México, given strong empirical evidence in favor of the log-linear relationship between $m$ and $i / 1+i$ that it produces. ${ }^{7}$ The exponent $\gamma$ is set to mimic the interest elasticity of money demand estimated at -0.15 , so that $\gamma=5.66$. $A$ is set so ${ }^{+}$it

\footnotetext{
${ }^{7} \mathrm{Kamin}$ and Rogers (1996) found that for the period 1988-94 there is a stable, error-correction specification of the demand for real M2 in Mexico as a function of $i$ and $V$. They also provide evidence of a strong cointegrating relationship between these two variables.
} 
the high-inflation, pre-stabilization steady state mimics the M2/GDP ratio (31.8 percent on an annual basis) and nominal interest rate (177 percent annually) at end-1987, when the last Mexican ERBS program started. M2/GDP rose gradually to 35.5 percent in 1994, and collapsed in 1995 . With all this in mind, the steady-state money demand equation can be solved for $A(A=0.19)$.

b) Preferences, Technology and Rebates: The values $\rho=0.786, \omega=0.5, \mu=-0.218, \sigma=2.61, \alpha T=0.42$, $\alpha N=0.34$ and $\delta=0.1$, are taken from the developing country, small open economy model calibrated in Mendoza (1995). $\mu$ and $\sigma$ reflect estimates from econometric studies for developing economies, $\rho$ is set so that households allocate 75 percent of their time to leisure in a model without money, and $\alpha T$ and $\alpha N$ reflect long-run averages computed with sectoral GDP data. $\phi=0.06$ is set to mimic the standard deviation of Mexican investment in an RBC model. Also, we assume that $\beta=\left(1+r^{*}\right)^{-1}$ with $r^{*}$ set at 6.5 percent per annum, so that there is no debt accumulation resulting from agents aiming to attain a target level of wealth, and $\eta_{m}=\eta_{S}=0$, reflecting the assumption that fiscal discipline is restored during the currency peg (i.e. $G=0$ ).

c) Hazard rate function: The hazard rate takes a J-shaped form consistent with the econometric studies by Garber and Blanco (1986), Goldberg (1994), and Klein and Marion (1994). Garber and Blanco's estimates are derived from a model of balance-of-payment crises applied to the Mexican devaluations of 1976 and 1982 . In the latter case, the authors estimate a probability of collapse at 0.2 early in 1977 , declining to near zero in about a year, rising slowly in 1978-79, and rising rapidly to about 0.3 before the collapse. Goldberg applied a similar approach to data for 1980-86, although after 1982 México did not follow an ERBS plan. She finds that probabilities of collapse oscillate between low and high and that before the 1982 collapse the probability of devaluation was roughly 1 . Klein and Marion use logit analysis to identify factors that influence the duration of currency pegs, without requiring a specific model of currency crises, in a panel of monthly data for 17 countries over the 1957-91 period. They' found strong evidence showing that real appreciation is a key determinant of the probability of devaluation and that this probability is J-shaped. Probabilities of collapse one month prior to the 
devaluation are as high as 0.89 , with $1 / 10$ of the estimates higher than $0.55 .^{8}$ Thus, these studies suggest a J-shaped hazard rate set below 0.5 when the program begins, falling to zero and rising to about 0.8 prior to the collapse. We also set ex-post duration at $J=24$ quarters, in line with the six-year duration of currency pegs observed in Mexico since 1970 (see Section 4).

\section{Model Simulations: Does Uncertain Duration Explain the Syndrome?}

This section examines the quantitative implications of uncertain duration. First we quantify the demand-side, uncertain-duration effects identified by Calvo and Drazen (1993). In the second stage we simulate the general equilibrium model and examine its welfare implications.

\section{Uncertain-Duration Effects in the Calvo-Drazen Trade Reform}

The model is reduced to represent an endowment, exchange economy in which consumer goods are imported paying a tariff $\tau$ set at 20 percent. The government announces and implements the abolition of tariffs $(\tau=0)$ at date $t=0$, but agents interpret this as a reform of uncertain duration. Thus, $z_{1}$ denotes the probability that $\tau=0.2$ at date $t+1$ given that $\tau=0$ at date $t$.

Consider the three specifications of $z_{t}$ plotted in Figure 2: (a) the perfect foresight case $\left(z_{t}\right.$ is always zero, except at date $J)$, (b) the flat hazard rate $(z$ is some positive constant, say 0.5 , until date $J$ in which it rises to 1 ), and (c) the J-shaped hazard rate. Figure 3 plots the corresponding state-contingent equilibrium paths for consumption under alternative specifications of rebates and values of $\boldsymbol{\sigma}$. The continuous (dotted) lines represent allocations under the assumption that trade reform continues (ends).

The perfect-foresight case reproduces the predictions derived by Calvo (1988). Consumption "booms" when the tariffs are abolished at 0 , and remains high until it collapses at date $J$. As Calvo and Mendoza (1994) show, for $\sigma>1$ consumption collapses to a point below (above) the pre-reform equilibrium if tariff revenue is (is not) rebated. If $\sigma=1$, consumption collapses exactly to the level it had prior to the trade reform. Under full rebates, the temporary tariff induces a pure substitution effec

${ }^{8}$ Note however that the Klein-Marion estimates make use of all the within-sample information to generate the ex-post probability of devaluation, whereas the Blanco-Garber and Goldberg studies are based on comparing a "shadow" exchange rate (i.e. a period-ahead forecast) to the actual prevailing peg. 
$-14-$

against savings (since future prices are expected to rise permanently at $J$ ), and hence the consumption profile is tilted toward the present for a given lifetime wealth. Without the rebate and $\sigma>1$, the trade reform induces a positive income effect in addition to the substitution effect, and hence the less pronounced collapse at date $J$.

The uncertain duration example with a flat hazard rate function confirms Proposition 1 in Calvo and Drazen (1993). Under incomplete markets and $\sigma>l$, consumption first booms and then gradually falls (rises) before the final collapse if tariff revenue is (is not) rebated. The intuition for this result follows from the income effects introduced by market incompleteness discussed earlier. Without rebates, there is some probability that tariffs will return between dates 0 and $J$, and thus at every date in this interval that free trade continues households are "pleasantly" surprised with a gain in permanent income by the amount of the nonrebated tariff revenue foregone. Consumption increases gradually as a result, until date $J$ arrives, when there is a sudden fall in consumption since forever after the probability of tariffs returning is exactly 1 . In the case with rebates these "pleasant" surprises do not exist. In contrast, the probability of policy reversal is an incentive to over-consume relative to a perfect foresight case (notice that the impact effect on consumption is stronger than under perfect foresight). If prices do not rise, households realize they over-consumed, and hence depleted their wealth too much, and thus the incentive to reduce consumption. Note also that with the flat, linear hazard rate function consumption dynamics are approximately linear.

The results for the J-shaped hazard rate illustrate the rich dynamics that the uncertain duration framework can produce. With rebates, the initial boom is followed by a quick fall into a plateau of high consumption that lasts until the collapse arrives. Similarly, without rebates there is a boom on impact, followed by an accelerated boom to a high consumption plateau that collapses at date J. In both cases there is a higher degree of nonlinearity in consumption dynamics relative to the case of the linear hazard rate. Thus, the shape of macroeconomic dynamics depends critically on the shape of the hazard rate function defining the probabilitiy of policy reversal. 
Uncertain Duration Effects in a Model of Exchange-Rate-Based Stabilizations

Consider next the benchmark general equilibrium model. Figure 4 plots state-contingent equilibrium dynamics as percent deviations from the pre-stabilization steady state. The J-shaped hazard rate produces $\mathrm{J}$-shaped dynamics in velocity and net exports, and inverted J-shaped (i.e. concave) dynamics in GDP, consumption, investment, labor supply, and the real exchange rate. These concave dynamics are very important to produce given the observation that boom-recession cycles, with recessions at times pre-dating devaluations, are typical of ERBS syndrome (see Rebelo and Végh (1995) and the case study for México in Section 4). It is straightforward to show, given (13) and $\beta=\left(1+r^{*}\right)^{-1}$, that if $z$, reaches 0 at the minimum of the hazard rate function (as it does in Figure 4), then the equality of intertemporal marginal utilities of $C^{T}$ will likely induce concave dynamics. In fact this is a necessary condition in a one-good model with endowments. In our model, however, $z_{t}>0$ at the minimum of the hazard rate function still yields similar concave dynamics as the $z_{t}=0$ case. What is required for the concavity result is that the hazard rate function be strictly convex. $z_{1}=0$ is not required because of the supply-side effects that derive from labor supply elasticity and the presence of investment expenditures in the transaction costs technology. These effects add to the steady-state supply-side effects of permanent disinflations examined in recent studies. The sensitivity analysis undertaken below shows in addition that the supply-side effects imply that a strictly convex hazard rate, while necessary, is not sufficient to ensure concave dynamics.

The sharp decline in velocity shown in Figure 4 is consistent with the observation that liquidity rises much faster than output in the early stages of a currency peg. This accelerated expansion of monetary aggregates has in turn been linked to banking fragility, and both banking fragility and the collapse of money demand that occurs at date $\mathrm{J}$ have been attributed a key role in generating balance-ofpayments crises (see Calvo and Mendoza (1996)). The trade balance as a share of GDP worsens markedly on impact, from a surplus of about 5 percent of GDP to a deficit of similar magnitude, and then it follows a J-curve pattern similar to that of the hazard rate, reaching almost 10 percent of GDP by the 
8th quarter after the plan starts. The booms in GDP, consumption and investment are also in line with ERBS syndrome, although the investment boom seems excessive. Investment rises more than consumption and GDP in the early stages of the program, and, more importantly, all three begin to decline before the peg collapses.

The benchmark model also generates a sharp real appreciation, of about 6 percent, in the first year of the program. The appreciation continues at a more moderate rate to reach 15 percent by the 10 th quarter, and then it stops and actually reverses to about 10 percent by the date of the collapse. The real exchange rate is determined by the interaction of demand and supply features, particularly the elasticity of substitution in consumption of traded and nontraded goods, $1 / 1+\mu$, the elasticity of leisure, $p$, and the share of labor income in production of nontradables, $\alpha N$. The value of $\mu$ used implies an elasticity $(1 / 1+\mu)$ of 1.28 , thus making $C^{T}$ and $C^{N}$ gross substitutes. $C^{T}$ rises (falls) faster than $C^{N}$ when both are booming (falling), causing the rise (fall) in $p^{N}$. Note also that the boom in $C^{N}$ can only be accomplished at the expense of reducing leisure, and so $L^{N}$ rises in tandem with the consumption boom.

Next we compare the results of the uncertain-duration model with those obtained in perfectforesight studies. Consider first the model of Reinhart and Végh (1995). Reinhart and Végh simulated consumption "booms" given observed temporary declines in nominal interest rates, the estimated duration of stabilization plans, and econometric estimates of $\sigma$, and using the closed-form solution for consumption in a one-good, endowment economy model with money entering via transaction costs. They found that for the model to predict increases in consumption similar to those observed in the data, the fall in interest rates needs to be substantial (in excess of 1500 basis points). Moreover, in this perfect-foresight model, consumption jumps on impact as the stabilization begins, and remains constant until it collapses when the program is abandoned.

Rebelo and Végh (1995) undertake a similar analysis but in the context of a two-sector, ge er:!equilibrium framework in which the credibility effect on the demand side is augmented by supply-side effects. They simulated a temporary currency peg known with full certainty to collapse in 10 quarters 
and found that the temporariness hypothesis underestimates significantly the magnitude of the consumption booms and real appreciations. The real exchange rate appreciates by about 5 percent at a nearly constant rate, consumption of tradables (nontradables) rises on impact also by about 5 percent and then it rises (falls) gradually until it collapses when devaluation arrives. Investment and real balances jump by 75 and 50 percent respectively on impact and remain constant until they collapse together with the currency.

The Rebelo-Végh simulations produce "smooth" consumption dynamics, instead of discrete jumps, despite the perfect-foresight nature of their model, because of the combination of (a) the slow adjustment of the capital stock resulting from adjustment costs, (b) the introduction of investment in the transaction costs technology, (c) the perfect substitutability of labor across sectors with Cobb-Douglas technologies, and (d) the use of the utility function proposed by Greenwood, Hercowitz and Huffman (1988), in which the marginal rate of substitution between consumption and leisure is independent of consumption, effectively eliminating the wealth effect on labor supply. ${ }^{9}$ The model proposed here shares features (a) and (b), and yet the perfect-foresight simulation examined below yields the discrete consumption jumps typical of perfect-foresight credibility models. Moreover, even with all four assumptions, investment and real balances in their model still display the sudden jumps typical of perfect-foresight models. In contrast, in the benchmark model with a J-shaped hazard rate smooth business cycles result only from uncertain duration.

The 15 percent real appreciation in our model is more than 3 times larger than those produced with perfect-foresight models, without requiring exogenous price rigidities. Differences across models on the magnitude of real appreciations depend critically on assumptions regarding sectoral labor mobility. ${ }^{10}$ If labor is perfectly mobile, as in Rebelo and Végh (1995), the real exchange rate is

\footnotetext{
${ }^{9}$ Rebelo and Végh (1995) also examined the implications of an isoelastic utility function like the ve we postulated, but found that labor supply exhibited a counter-factual decline. Note also that in their model government rebates seignorage, but the resources lost to transaction costs are a pure excess burden. ${ }^{10}$ Alternatively, Uribe (1995) shows that shifts in nontradables investment demand, driven by time-to-build effects, can produce gradual and sizable real appreciation regardless of labor mobility and credibility effects.
} 
governed by the Balassa-Samuelson condition--changes in $p^{N}$ must reflect sectoral labor productivity changes. As a result, large labor reallocations or productivity shifts are required to generate large real appreciations, suggesting that a steeper transformation curve between production of tradables and nontradables is more realistic. Breaking away from the Balassa-Samuelson model also seems critical in light of evidence showing its counter-factual implications (see Asea and Mendoza (1994)). One alternative is to assume there is a fixed endowment of nontradables, which results in the opposite extreme in which the real exchange rate is demand-determined by the value of $\mu$ (as in the classic models of Greenwood (1984) and Frenkel and Razin (1987)). An alternative, less extreme assumption, is the one adopted here, which limits sectoral mobility of labor but does not eliminate a supply-side response in the nontraded sector. Clearly, this is also restrictive as in reality labor in the two sectors is substitutable to some degree. Note, in addition, that large real appreciations in our model also require incomplete markets and the wealth effects of nonrebated seignorage and transaction costs.

\section{Sensitivity Analysis}

Figure 5 provides charts summarizing the results of an extensive sensitivity analysis. Plots for dynamics of the real exchange rate, the trade balance-output ratio, aggregate consumption, and investment are presented for 10 alternative model specifications. The first one recreates the benchmark model and the rest are for the following experiments: (1) flat hazard rate, set at 28 percent to reflect the same unconditional expectations of devaluation as the $\mathrm{J}$-shaped hazard rate, $(2)$ perfect-foresight $\left(z_{t}=0\right.$ for $0 \leq t<J$ and $z_{t}=1$ for $\left.J=24\right)$, (3) full rebates of seignorage and transaction costs $\left(\eta_{s}=\eta_{m}=1\right)$, (4) inelastic labor supply $(\rho=0),(5)$ unitary elasticity of substitution between traded and nontraded goods $(\mu=0),(6)$ reduced intertemporal elasticity of substitution ( $1 / \sigma$ falls from $1 / 2.6$ to $1 / 5)$, (7) extended time horizon (the program fails after 9 years, $J=36$ ), (8) calibration of money demand based on M1 velocity, and (9) non-zero long-run probabilities of success of the stabilization program (the long-run probability of continuation of the peg at $J$ is set at 10 and 50 percent). The shooting routine ensures that all the 
simulations are based on terminal conditions on foreign assets consistent with the same initial foreign asset position at the beginning of the currency peg.

The flat hazard rate case extends the results of the Calvo-Drazen model to the general equilibrium model with money as a means to economize transaction costs and supply-side transmission mechanisms. First, under incomplete markets, no rebates, and $\sigma>1$, a stabilization of uncertain duration leads to an increase in consumption on impact, followed by a gradual boom prior to the collapse. Second, a linear hazard rate produces near-linear macroeconomic dynamics.

The perfect-foresight simulation confirms that, in the absence of uncertain duration, the model behaves as the typical credibility model, despite adjustment costs and the strengthened non-neutralities of money induced by supply-side effects. Consumption, investment, and the real exchange rate jump on impact to higher constant levels as the program begins, and collapse when the program ends.

The model with full rebates produces dynamics qualitatively similar to those of the benchmark model. Quantitatively, however, the model with full rebates produces small booms in consumption and the real exchange rate, and a large fall in net exports. With rebates, only the tax-like distortion of uncertain duration on relative prices, acting via intertemporal substitution, is at work. Thus, the comparison of the benchmark and full-rebates cases shows that the wealth effects allowed by market incompleteness and no rebates are critical in enabling the model to produce large booms and real appreciations. In a similar vein, Uribe (1995) shows that the permanent-income effect of transactioncosts rebates rises from 2 to 15 percent of GDP as monthly inflation rises from 1 to 50 percent. Note also that under no rebates there is a transitory cut in $G$ for the duration of the currency peg, which is reminiscent of the fiscal-induced wealth effects used by Helpman and Razin (1987) and Drazen and Helpman (1988) to explain the real effects of disinflations.

The preference parameters $\sigma$ and $\rho$ play a crucial role. Inelastic labor supply alters the shape of consumption and real-exchange-rate dynamics so that an initial boom is followed by a period of stability in both, prior to a continuation of the boom, instead of the gradual decline observed in the benchmark 
model. Here, strict convexity of the hazard rate function fails to yield concave consumption dynamics. If the intertemporal elasticity of substitution falls to $1 / 5$, real exchange rate dynamics are altered in the same way as in the case of inelastic labor, but consumption dynamics are not significantly different from those in the benchmark model. The difference results from the supply response in the nontradables sector that is present with reduced intertemporal elasticity of substitution, and absent with inelastic labor. In contrast to $\sigma$ and $\rho, \mu$ and $J$ do not alter the outcome of the simulations significantly--except for the fact that $J=36$ produces a larger and more sustained real appreciation than the benchmark model. The move to $(1 / 1+\mu)=1$ is not a radical departure from the 1.28 elasticity in the benchmark. However, this elasticity has the potential for affecting significantly sectoral consumption allocations and the behavior of the real exchange rate if it is allowed to vary more widely, as evident from equilibrium condition (10).

The model calibrated to M1, rather than M2, is intended to control for the fact that while M2 is a good proxy for money balances used in transactions, it includes interest-bearing deposits on which seignorage is collected at a rate smaller than the rate of inflation (or devaluation). Thus, the M2 specification approximates well transaction costs, but exaggerates seignorage, while the M1 specification is better at measuring seignorage but underestimates transaction costs. The results show that transaction costs rebates play a crucial role in the benchmark model's ability to produce large booms and large real appreciations.

The assumption that the program fails with probability 1 after 6 years is not crucial for the positive predictions of the benchmark model. If the eventual probability of currency collapse after 6 years is $1,0.9$, or even 0.5 , the dynamics before the 20 th quarter are nearly identical in the three experiments, although after that date they differ markedly. This result shows also that ERBS syndrome occurs regardless of the long-run probability of success of the program. The normative predictions of the model can, however, be significantly affected by the potentially large differences in macroeconomic dynamics after the 20 th quarter. 
One additional element that may alter the results is the fact that the probability of devaluation may be updated given the state of the economy. ERBS syndrome is likely to influence the process by which agents form their expectations on the sustainability of the currency peg, leading them to grow pessimistic about its prospects as the stabilization program progresses. Indeed, Klein and Marion (1994), Frenkel and Rose (1996), and Kaminsky and Reinhart (1996) show that real appreciations provide useful information to anticipate currency crashes. Thus, instead of modelling an exogenous hazard rate function, one should consider an endogenous hazard rate and compute a rational expectations equilibrium in which the dynamics of the real exchange rate, and other determinants of currency collapse, influence the probability of devaluation. We analyze this in a separate paper, which considers a probability of collapse that depends on the degree of real appreciation relative to the pre-stabilization level of the real exchange rate." Preliminary results suggest that the J-shaped hazard rate function can be an endogenous outcome of the model.

\section{Welfare and Policy Implications}

If uncertain duration causes ERBS syndrome, policy-makers face a serious challenge. On the one hand, the high-inflation equilibrium embodies the distortion on money balances and its spillover into transaction costs and real activity, which make disinflation policy desirable. On the other hand, a lessthan-fully-credible stabilization program introduces new distortions, which make disinflation policy undesirable. In the classic case of the perfect-foresight credibility literature, without supply-side effects and with full rebates (i.e. Calvo (1988)), lack of credibility is always costly because it is identical to a temporary tax on savings with the proceedings rebated to households. But in models like the one studied here, several distortions are at work, and welfare assessments are more complex. The previous analysis

\footnotetext{
"The solution of the model is complicated by the fact that we need to compute a sequence of the real exchange rate yielding a hazard rate function that supports the same real exchange rate dynamics. This requires extending the algorithm to add iterations over hazard rate functions. We begin with a guess for thi: function, and solve equilibrium dynamics as before using the resulting path of the real exchange rate to update the hazard rate. We have found numerical solutions for this problem, but cannot prove that the solutions always exist and are unique.
} 
thus needs to be extended to (a) provide a quantitative assessment of the welfare implications of different strategies (no stabilization, credible and incredible disinflations), and (b) if the first step suggests that stabilization is desirable, consider policies to counteract the distortions induced by uncertain duration.

Quantifying the welfare implications of uncertain duration is a straightforward extension of the simulations conducted earlier. We computed welfare effects as a function of the ex post duration of the currency peg under alternative hazard rate functions for the cases with and without rebates. These welfare effects, plotted in Figure 6, were computed as follows. Consider a policy-maker at any date $t \geq 0$, at or after the beginning of a stabilization plan, that assesses the welfare effect of the currency peg given that the stabilization program has lasted up to date $t$. He ponders the benefits of stabilization by comparing the familiar compensating variations in consumption (see Lucas (1987)) that capture the change in expected lifetime utility that renders agents indifferent between the allocations implied by an ERBS of uncertain duration and the continuation of the high-inflation status quo. These calculations take into account the state-contingent allocations of consumption and leisure, and the associated probabilities. For the welfare effect at $t$, uncertainty up to date $t$ has been resolved, so the realizations of $C$ and $\ell$ that enter into the computation of expected lifetime utility from dates 0 to $t$ are known, and expectations are used only for dates from $t+l$ to $J$. Thus, the vertical intercepts of the curves plotted in Figure 6 (listed in Table 1) measure the ex ante welfare effects that evaluate the disinflation program at the outset. The welfare effects for the 24th quarter, in contrast, measures the ex post welfare effect of the policy assuming that the program in fact lasted 6 years. In between the two, the welfare effects assess the value of a currency peg that has lasted t periods and may or may not fail until the 24 th quarter. The ex ante measures tell us about the desirability of disinflation in general, while the rest illustrate how uncertain duration affects welfare calculations. 
The first important feature of the welfare analysis is the fact that temporary programs always produce a welfare gain. ${ }^{12}$ This deviates from perfect-foresight credibility models with rebates and no supply-side features, in which lack of credibility is a temporary, welfare-reducing tax. Indeed, for a perfect-foresight incredible trade reform in an endowment economy with rebates to yield the same $e x$ ante lifetime utility as the pre-reform steady state with tariffs, consumption would need to rise by 0.14 percent in every period (i.e. the welfare cost is 0.14 percent ). This compares to a negative welfare cost of -0.33 (i.e. a welfare gain of 0.33 ) percent in the perfect-foresight, general-equilibrium model of ERBS programs with rebates. Thus, it follows that currency pegs, even if temporary, are better than continued high inflation because of the supply-side effects caused by elastic labor supply and capital accumulation.

The second key result of welfare calculations is that uncertain duration embodies much larger welfare costs than the standard perfect-foresight credibility problem, particularly if the policies are compared at the time the currency peg is introduced. These ex ante comparisons show that uncertain duration entails welfare gains that are equivalent to $1 / 4$ to $1 / 6$ those produced under perfect foresight, with or without rebates and regardless of the curvature of the hazard rate function. Thus, while temporary programs are beneficial, uncertain duration induces large additional distortions with marked adverse effects on economic behavior. As welfare assessments are corrected for the resolution of uncertainty (i.e. for higher values of $t$ ), welfare gains under uncertain duration rise and almost converge to those obtained under perfect foresight. This is because for every date that the program lasts, the computations consider as "accrued" the realizations of consumption and leisure in the "good" state of nature in which the currency peg continued, and do not weight them by the complement cf the probability of devaluation. Figure 7 plots the state-contingent dynamics of consumption and leisure under the different policy regimes that help to clarify this argument. The "speed of convergence" depends on the curvature of the hazard rate function. With a flat hazard rate, welfare rises at a nearly

\footnotetext{
${ }^{12}$ Uribe (1996) obtains a similar result by showing that in the presence of currency substitution temporary programs can generate welfare gains even under full rebate of seignorage income.
} 
constant rate, reflecting the quasi-linear dynamics that it produces. The J-shaped hazard rate yields a highly nonlinear welfare path. Welfare at first rises faster than with the flat hazard rate, but then it remains nearly unchanged for about two years before starting to rise again. Thus, these results show that uncertain duration is very costly, and that under a convex hazard rate there may be periods during which the program may continue without any benefit to social welfare. Our analysis does not rule out, however, the possibility that the welfare path may be upward sloping (at least locally) for some nonlinear hazard rate function. Moreover, this analysis of the resolution of uncertainty is of little use for the policymaker, who decides whether to start an ERBS program at date $t=0$ using only the ex ante welfare costs.

Comparing the ex ante welfare effects in Table 1, it transpires that the wealth effects under no rebates and incomplete markets have significant welfare implications. The welfare gains of temporary stabilizations range between 0.05 and 0.33 percent under full rebates, and thus are much smaller than those obtained in the absence of rebates, which range from 1.1 to 7.4 percent. Note, however, that the proportion by which welfare gains under perfect foresight exceed those of uncertain duration is nearly the same with and without rebates. Table 1 also suggests that, for welfare analysis, the supply-side effect introduced by labor supply elasticity is less important than that due to capital accumulation. This is conjectured on the basis that welfare gains for a model with inelastic labor are similar to those for the benchmark model. The ex ante welfare gain under the convex hazard rate function is $0.07(1.44)$ percent with inelastic labor and with (without) rebates, compared to 0.08 (1.57) percent in the benchmark model Following Calvo and Mendoza (1994), it is also important to note that once one breaks away from the basic credibility model, comparing welfare under a temporary program with welfare under a fully-credible program is important. This comparison is trivial in the basic model because in it the allocations under the status quo and a fully-credible policy reform are identical. In the benchmark model, in contrast, the ex ante welfare effect of uncertain duration is equivalent to a 1.57 percent gain in permanent consumption relative to the pre-stabilization equilibrium, but that welfare gain is 22 percentage points smaller than the 23.7 percent gain produced by a fully-credible stabilization. Thus, 
credible disinflation programs are still significantly more desirable than temporary programs.

We conclude with some comments on policy alternatives. First, if all policies are equally incredible, the policy message is simple: exchange-rate-based disinflations, even if incredible, are still worth implementing because the net effect of credibility distortions is measured to be smaller than the high-inflation distortion. Second, if some policies are credible, they may be useful in countering the adverse effects of lack of credibility and hence make disinflation programs even more beneficial. For example, a policy recommendation that emerges from our analysis is that if tax policy is credible, a properly-chosen consumption tax can be very effective in controlling credibility-induced business cycles. In the basic case in which temporary reform is always socially costly, one can construct a sequence of consumption taxes that completely eliminates the credibility problem yielding the Pareto optimal equilibrium. Note, however, that in practice optimal tax design would require information on how incredible the stabilization policy is (i.e. an estimate of $z_{t}$ ), and that assessing how pervasive is the lack of credibility using macroeconomic data may be very difficult given the effects of other sources of business cycles (see Calvo and Mendoza (1994)).

\section{A Case Study: The Mexican Experience in the Post-War Period and the 1994 Crash}

This section examines the empirical regularities that characterize ERBS syndrome in México from the perspective of the uncertain duration model. The analysis of the Mexican case is an interesting addition to the comprehensive cross-country studies by Kiguel and Liviatan (1992) and Végh (1992) for three reasons. First, México's currency collapses co-existed with a solid political structure, in contrast with the major political crises that often accompany economic crises in other developing countries. Thus, in México lack of credibility did not reflect uncertainty on the duration of political institutions, but mainly uncertainty about the future course of economic policies. Second, the analysis of México's ERBS episodes highlights certain aspects of the process, such as the varying duration of currency pegs and varying speed of economic expansion and real appreciation, on which the uncertain duration framework sheds some light. Third, instead of conducting a cross-country analysis, we focus on México's six 
episodes of ERBS syndrome since 1945. Thus, the usual contrast between cross-sectional and time-series analyses applies. Note, however, that our objective is not to obtain the best possible match to Mexican data, as that would require adding other major sources of business cycles that would make it impossible to examine uncertain-duration effects in isolation.

The first part of the empirical analysis covers 1945-94 using annual data, and the second part uses quarterly data for the last ERBS episode (1988-94). The analysis of the 1988-94 episode is useful because reforms implemented in this period brought México closer to the environment of openness to global markets and flexible prices assumed in the model, in sharp contrast to the expansionary policies and excessive government intervention of the past. Also, the quarterly data allow us to use time-series methods to isolate the potential contribution of credibility to business cycles. Data on prices and exchange rates were obtained from the IMF's International Financial Statistics, and national accounts data were retrieved from Indicadores Economicos of Banco de México. The real exchange rate (RER) in the $1945-94$ sample is a bilateral CPI-based index with $1970=100$ and defined as P/EP*, where $\mathrm{P}$ and $\mathrm{P}^{*}$ are end-of-period Mexican and U.S. CPIs respectively, and E is the nominal exchange rate in terms of nuevos pesos per U.S. dollar. RER in the quarterly sample is the IMF's measure of the trade-weighted, CPI-based real effective exchange rate.

Figure 8 plots the evolution of annual exchange rates. The logarithm of the nominal exchange rate is in the left scale, and the RER index is in the right scale. Figure 8 shows sharp real appreciations during fixed-exchange-rate regimes, typical of ERBS syndrome, prior to large real depreciations that coincided with the collapses of the currency in $1949,1954,1976,1982$, and $1994 .^{13}$ The real appreciations occurred rapidly, over 2 to 4 years, and in two instances periods of real-exchange-rate stability existed in between sharp appreciations--in the 1960 's era of the so-called "stabilizing development" and in 1989-90. ${ }^{14}$

\footnotetext{
${ }^{13} 1987$ is an exception in which the peso collapse was not preceded by exchange-rate-based stabilization. ${ }^{14}$ It is also interesting to note that Mexican inflation was closer to U.S. inflation under the high levels of protection of the 1960 s than under the substantially more open regime of the 1990 s.
} 
This "eye-of-the-hurricane" feature of the real appreciation poses a serious challenge for models of ERBS syndrome. If real appreciation followed from conventional price inertia inducing persistent inflation, the real exchange rate should appreciate at a sustained rate. Calvo and Mendoza (1996) and Aspe (1993) argue in addition that México's real appreciation was not just a case of general price inertia because it was driven by a slow deceleration in inflation of nontradables goods prices, and because México's social pact broke backward indexation practices and resulted in large dispersion in sectoral real wages. Alternatively, if lack of credibility under perfect foresight or market completeness were the cause of the real appreciation, the real exchange rate should display discrete jumps around the dates of adoption and abandonment of currency pegs, as shown in Figure 6. In contrast, the simulations of the benchmark model show that uncertain duration, using a convex hazard rate function consistent with empirical evidence based on Mexican data (e.g. Blanco and Garber (1986)), provides an explanation for temporary stability of the real exchange rate. Depending on preference parameters, it is also possible to obtain either a real exchange rate that continues to appreciate or that depreciates slightly after the period of stability.

Consider next the cyclical behavior of real GDP per capita and its expenditure components. Figure 9 plots the logarithm of real per-capita GDP and two conventional estimates of its long-run trend; the cubic time trend $\left(\mathrm{T}^{3}\right)$ and the random-walk $(\mathrm{RW})$ trend. Both trends show a large structural break in México's growth after 1980 that raises important issues, some of which go beyond the scope of this study. For instance, the protracted recession into which México fell in the aftermath of the debt crisis, and from which it has yet to recover, is an issue for which no clear explanation exists. ${ }^{15}$ Roughly the same structural break is identified using either the Hodrick-Prescott (HP) filter or the Baxter-King bandpass (BP) filter.

\footnotetext{
${ }^{15}$ This phenomenon is common to other countries that experienced large and persistent adverse shocks to the world interest rate and the terms of trade in the 1980s. These shocks can cause protracted recessions and reduce long-run growth in economies dependent on international trade (see Mendoza (1995) and (1996)).
} 
México's "long great depression" also raises important issues for the choice of filter used to define business cycles, which in turn plays a key role in defining ERBS syndrome. The BP filter, designed here to isolate information contained in frequencies between 2 and 8 years, and the RW filter track more closely the structural break than the $\mathrm{T}^{3}$ and HP filters, and hence produce smaller cycles. ${ }^{16}$ The cyclical components of the four filters are stationary. ${ }^{17}$ Thus, these filters define business cycles as relatively low-frequency ( $\mathrm{T}^{3}$ and HP filters), mid-frequency (BP filter), or high-frequency (RW filter) components of the data, while maintaining the condition that cyclical components are stationary. Since there is no clear "best" filter, the cyclical components of the four filters are examined.

Figures 10 plots business cycles of key macroeconomic aggregates and Table 2 reports cyclical co-movements. The qualitative features of México's cycles are similar to those observed in other developing countries (see Mendoza (1995)). Fixed investment (I) and the net exports-GDP ratio (NX/Y) are significantly more volatile than GDP, while private consumption $(\mathrm{C})$ is only slightly more volatile. ${ }^{18}$ $\mathrm{C}$ and $\mathrm{I}$ are procyclical and $\mathrm{NX} / \mathrm{Y}$ is countercyclical, and all four variables (GDP, $\mathrm{C}$, I, and NX/Y) exhibit positive persistence ${ }^{19}$ Business cycle volatility, measured in terms of percent standard deviations, is higher the lower the frequency of the filter used. However, the standard deviations of $\mathrm{C}$ and $\mathrm{I}$ relative to GDP are similar for the $\mathrm{BP}, \mathrm{HP}$, and $\mathrm{T}^{3}$ filters, while for the $\mathrm{RW}$ filter the relative variability of $\mathrm{C}$ is larger and that of I is smaller than with the other filters. Thus, as a first approximation, the lowerfrequency filters produce larger, more persistent, and more correlated business cycles, but the differences across filters are not substantial.

\footnotetext{
${ }^{16} \mathrm{The} \mathrm{T}^{3}$ filter and the HP filter with the smoothing parameter set at 100 produce highly correlated cyclical components for GDP, $\mathrm{C}$, and $\mathrm{I}$. The correlations exceed 0.91 in all cases.

${ }^{17}$ The BP and HP filters exclude unit roots by design, and for the RW and $\mathrm{T}^{3}$ filters ADF tests rejected unit roots at the 1-percent confidence level with 3 lags.

${ }^{18} \mathrm{C}$ includes durables, which often results in larger consumption fluctuations relative to GDP.

${ }^{19} \mathrm{ADF}$ tests rejected the hypotheses that $\mathrm{NX} / \mathrm{Y}$ and RER contain unit roots, and hence it is unclear whether they should be filtered. Co-movements for $\mathrm{NX} / \mathrm{Y}$ and RER in the BP and $\mathrm{T}^{3}$ columns of Table 2 were computed in levels, while NX/Y and RER were filtered in the HP and RW columns. The Table shows that cyclical indicators are not too dependent on whether these variables are filtered or not.
} 
Table 2 also shows that the variability of RER is much larger than that of the other variables-relative to GDP the fluctuations of RER are at least 6.7 times larger than those of the other variables. There is little evidence that real appreciations are correlated with GDP fluctuations, while $\mathrm{NX} / \mathrm{Y}$ and RER display strong negative correlation. Thus, real appreciations coincide on average with a widening trade imbalance relative to GDP, reflecting a strong positive correlation between real appreciation and domestic absorption. This feature of ERBS syndrome is replicated by the uncertain duration model. Figure 6 shows that uncertain duration generalily produces a negative reiationship between RER and the GDP share of net exports.

This discussion of cyclical co-movements is intended as a general description of Mexican business cycles, rather than as the foundation of a "moment-matching" exercise typical of RBC analysis, because the quantitative experiments conducted in Section 3 focus on simulated time-series paths rather than on cyclical co-movements. Initial conditions were set to mimic roughly those prevailing before ERBS programs start, with the intent to examine whether simulated macroeconomic dynamics resemble those observed in the data. This approach seems adequate in the Mexican case because the data show that México goes through the complete expansionary phase of the cycle during each fixed-exchange-rate regime (except in the long-lasting currency peg covering 1955-76), so that the size of the booms and real appreciations associated with ERBS episodes can be identified by examining Figures 8 and 10. A typical example is the 1976-82 episode. Between 1976 and 1981, RER appreciated by 38 percent, deviations from trend in I widened by 30 percentage points and those for C and GDP widened by 8 percentage points (according to the BP filter), and $\mathrm{NX} / \mathrm{Y}$ changed from virtual balance to an 8 percent deficit.

Figure 11 plots cyclical components of quarterly data for the period 1983:1-1994:4. The chart for the trade-weighted RER shows that, after a sharp initial appreciation in the first semester of 1988 , following the beginning of the currency peg in February, RER remained almost constant until 1990:4. In 1991:1 the real appreciation started again, so that by the December 1994 devaluation the real exchange rate appreciated by 35.4 percent relative to $1988: 1$. By end- 1993 the real appreciation in fact reached 
46.8 percent, so RER fell by about 10 percentage points in the year before to the devaluation. Similarly, the dewtions from trend in I, GDP, and C widened considerably between 1988 and 1992, but in 1993 all three cyclical indicators fell below trend. ${ }^{20}$ Interestingly, the size of the booms in GDP, expenditures, and the real appreciation are very similar to those observed in the 1976-82 episode.

In assessing the model's performance. we acknowledge that actual business cycles are caused by' several factors in addition to lack of credibility, such as the collapse of oil prices and the rise in world interest rates that hit México in 1982. Thus, we do not expect uncertain duration to explain in full Mexican business cycles and real appreciations, and ask instead what fraction of them can it explain. A finding that a large fraction can be explained by uncertain duration favors the model, without rejecting the hypothesis that other sources of business cycles are relevant. If only a negligible share of observed fluctuations can be explained by the model, however, one should conclude that credibility is of little relevance. Another reasonable strategy is to gauge the contribution of lack of credibility to explain ERBS syndrome in the data by isolating the potential contribution of credibility effects from the effects of other sources of business cycles using VAR methods (see Schmitt-Grohe (1995)). We computed variance decompositions of a parsimonious VAR system that uses the interest-rate spread between Mexican and U.S. treasury bills as a measure of the probability of devaluation and default. GDP, NX/Y, RER, and real M2 enter as endogenous and the terms of trade are exogenous. ${ }^{21}$ The exercise uses 2 lags as suggested by maximization of the Akaike Information Criterion. The results show that the interest differential explains about 40 percent of the variability of RER, GDP, NX/Y, and real M2 over 24 quarters. Unfortunately, because the interest differential is almost perfectly correlated with the Mexican interest rate, and the latter was influenced by sterilized intervention of large capital flows during 199094, the differential is at best a noisy measure of the "market" expectations of the sustainability of the peg.

\footnotetext{
${ }^{20}$ Since the period examined here excludes the sharp structural break in GDP noted earlier, a quadratic trend produces stationary cyclical components. ADF tests show that these components do not include unit roots. ${ }^{21}$ This VAR analysis borrows heavily from a similar exercise in Calvo and Mendoza (1996):
} 
Given the overall size of ERBS booms and real appreciations documented for México, and the estimate of the credibility component provided by the VAR, we conclude that an uncertain-duration model that produces an 18 percent real appreciation, consumption and GDP booms in excess of 2 percent, and investment booms in excess of 5 percent would be in line with the most recent Mexican experience. The 15 percent real appreciation produced by the benchmark model is less than $1 / 2$ the real appreciation observed in México during 1988-94 or 1976-82, but is close to the 18 percent credibilityinduced real appreciation measured using the VAR. The model also mimics the data in that RER is stable in the middle of the program and depreciates slightly prior to the collapse. The fluctuations in GDP and the trade deficit are also consistent with Mexican data, as is the fact that recessions may start prior to the collapse of the currency. In contrast, and contrary to the findings of perfect-foresight studies, the booms in tradables consumption and investment seem larger than those observed in the data.

In addition to the role of sources of business cycles ignored by the model, the match between the model and the data can be affected by the structure of parameters set in the calibration. As shown in the sensitivity analysis. assumptions on the size of rebates (which ultimately reflect the stance of fiscal policy), the shape of the hazard rate function, the elasticities of intertemporal substitution and labor supply, and the nature of financial assets that conform transaction balances, are key for the performance of the model.

\section{Concluding Remarks}

This paper shows that uncertain duration of an exchange-rate-based stabilization produces boomrecession cycles, worsening external deficits, and sharp real appreciations similar in magnitude to those that affect chronically countries that adopt disinflation programs based on fixed exchange rates. The analysis is conducted by simulating numerically the equilibrium dynamics of a general equilibrium model of a two-sector, small open economy with incomplete markets. Devaluation is modelled as an event to which agents assign an exogenous probability of occurrence, instead of being fully-anticipated as in the traditional credibility literature, and a backward-recursion algorithm is used to compute 
equilibrium dynamics allowing for full or partial rebate of seignorage and transaction costs. The experience of México in the post-war period, which includes six fixed-exchange rate regimes, is examined as a case study.

This approach to model lack of credibility as a problem of uncertain duration has been shown in theory to alter the predictions of conventional perfect-foresight, partial-equilibrium credibility models. However, the quantitative implications of the approach and its positive and normative predictions in a general equilibrium setting were unexplored. Our results suggest that uncertain duration may help to explain the actual experience of countries where, as in México in 1994, currency pegs fail under the pressure of large external deficits and overvalued exchange rates despite successful efforts to dismantle indexation and reduce fiscal deficits. The model explains key features of the syndrome of exchange-ratebased stabilizations without price or wage rigidities, or borrowing constraints.

The observation that devaluation probabilities are "J-shaped," borrowed from the empirical literature on balance-of-payments crises, is critical for the quantitative success of the uncertain duration framework. The shape of macroeconomic dynamics during a currency peg is heavily influenced by the shape of the hazard rate function that governs devaluation probabilities. Linear hazard rates yield quasilinear dynamics, while strictly convex hazard rates are a necessary (though not sufficient) condition to produce the concave dynamics observed in private expenditures and real appreciations. The "J-shaped" hazard rate also allows the model to mimic periods of temporary real-exchange-rate stability in between periods of sharp real appreciation, and recessions that pre-date currency collapses.

Wealth effects introduced by the incompleteness of financial markets, under the assumption that seignorage and transaction costs are not fully rebated, are also crucial for the model's performance. This is reminiscent of theoretical work on the real effects of disinflation that emphasizes wealth effects resulting from inconsistencies between fiscal and exchange-rate policies. Because of the wealth efferts, uncertain duration entails large welfare costs compared to the negligible welfare costs of credibility obtained under perfect foresight. 
The general equilibrium nature of the model implies that uncertain duration, which acts like a random tax on savings, affects both the supply and demand sectors of the economy. As a result, supplyside effects that have been examined for fully-credible disinflation plans, which operate via the leisureconsumption margin and the capital accumulation choice, also influence markedly the dynamics of uncertain duration models. Because of these effects, particularly the investment effect, exchange-ratebased stabilizations of uncertain duration are generally welfare-improving, relative to an initial highinflation equilibrium. These stabilizations are still very inferior to fully-credible stabilizations, and hence policies aimed at enhancing the credibility of currency pegs, or at lessening the impact of the taxlike distortion due to uncertain duration are desirable.

Our results also show that, despite the eventual success or failure of stabilization plans, and even in environments of perfect capital mobility, flexible prices, and fiscal and monetary discipline, stabilizations go through difficult stages in which the exchange rate is highly overvalued and the current account deficit is large because agents doubt the intentions of policy-makers. Policy lessons must then be drawn carefully, as devaluation by itself is not a permanent solution for real overvaluation and large trade deficits.

Before concluding, it is worth noting that while uncertain duration may help to explain Mexican macroeconomic dynamics between 1988 and 1994, it seems insufficient to explain the violence of the financial collapse and economic recession that hit México in 1995. As noted in the August, 1996 symposium issue of the Journal of International Economics, several researchers share the view that México-style crises are magnified by elements of self-fulfilling crises and "herding" behavior in global markets, which in México led to massive runs on a large stock of dollar-denominated public debt. 


\section{References}

Asea, Patrick, and Enrique G. Mendoza (1994), "The Balassa-Samuelson Model: A General Equilibrium Appraisal," Review of International Economics, vol. 2, pp.244-267.

Aspe, Pedro (1993), Economic Transformation: The Mexican Way, MIT Press, Cambridge: MA.

Blanco, Herminio, and Peter M. Garber (1986), "Recurrent Devaluation and Speculative Attacks on the Mexican Peso," Journal of Political Economy, v. 94, p. 148-166.

Calvo, Guillermo A. (1986), "Temporary Stabilization: Predetermined Exchange Rates," Journal of Political Economy, v. 94, pp.1319-1329. v. $35,461-473$.

(1988), "Costly Trade Liberalizations: Durable Goods and Capital Mobility," IMF Staff Papers, , and Allan Drazen, (1993) "Uncertain Duration of Reform: Dynamic Implications," Working Papers in International Economics No. WP 4, Department of Economics, Center for International Economics, University of Maryland at College Park.

, and Enrique G. Mendoza (1994), "Trade Reforms of Uncertain Duration and Real Uncertainty: A First Approximation," IMF Staff Papers, vol. 41, pp.555-586.

and Enrique G. Mendoza (1996), "México's Balance-of-Payments Crisis: A Chronicle of a Death Foretold," forthcoming, Journal of International Economics.

Dornbusch, Rudiger (1982), "Stabilization Policies in Developing Countries: What have we Learned?" World Development, vol. 10, pp. 701-708.

(1983), "Real Interest Rates, Home Goods, and Optimal External Borrowing," Journal of Political Economy, v. 91, pp. 141-153.

Drazen. Allan and Elhanan Helpman, (1988), "Stabilization with Exchange Rate Management under Uncertainty," in E. Helpman, A. Razin, and E. Sadka eds. Economic Effects of the Government Budget, MIT Press. Cambridge:MA, pp.310-327.

Edwards, Sebastian (1993), "Exchange Rates as Nominal Anchors," Review of World Economics, vol 129, no. I, Kiel Institute of World Economics, pp. 1-32.

(1996), "The Mexican Crisis in Historical Perspective," forthcoming American Economic Review: Papers and Proceedings.

Fernandez, Roque B. (1985), "The Expectation Management Approach to Stabilization in Argentina, 1976-82", World Development, August, v.13, pp. 871-92.

Frankel, Jeffrey and Andrew K. Rose, (1996), "Currency Crises in Emerging Markets: An Empirical Treatment," forthcoming, Journal of International Economics. 
Frenkel, Jacob A. and Assaf Razin (1987), Fiscal Policies in the World Economy, MIT Press, Cambridge.

Goldberg, Linda S. (1994), "Predicting Exchange Rate Crises: México Revisited," Journal of International Economics, v. 36, pp. 413-430.

Gomez-Oliver, Antonio (1981), Politicas Monetaria y Fiscal de México: La Experiencia desde la Posguerra, 1946-1976, Fondo de Cultura Economica, México City, México.

Greenwood, Jeremy (1983), "Expectations, the Exchange Rate and the Current Account," Journal of Monetary Economics, vol. 12, pp. 543-569.0

(1984), "Non-traded Goods, the Trade Balance, and the Balance of Payments," Canadian Journal of Economics, vol. 17, pp. 806-823

Zvi Hercowitz, and Gregory Huffman, (1988), "Investment, Capacity Utilization, and the Real Business Cycle," American Economic Review, vol. 87, pp.402-417.

Helpman, Elhanan and Assaf Razin (1987), "Exchange Rate Management: Intertemporal Tradeoffs," American Economic Review, vol. 77, pp.107-123.

Kaminsky, Graciela and Carmen M. Reinhart (1995), "The Twin Crises: The Causes of Banking and Balance-of-Payments Problems," mimeo, Board of Governors of the Federal Reserve System.

Kamin, Steven and John H. Rogers (1996), "Monetary Policy in the End-Game to Exchange-Rate-Based Stabilizations: The Case of México," forthcoming, Journal of International Economics.

Kiguel, Miguel and Nissan Liviatan (1992), "The Business Cycle Associated with Exchange Rate Based Stabilization," World Bank Economic Review, vol. 6., pp. 279-305.

Klein, Michael W. and Nancy P. Marion, (1994) "Explaining the Duration of Exchange-Rate Pegs," unpublished manuscript, Department of Economics, Dartmouth College.

Lahiri, Amartya (1995), "Exchange-Rate-Based Stabilization Under Real Frictions: The Role of Endogenous Labor Supply," mimeo, Department of Economics, UCLA.

Lucas Jr., Robert E. (1987), Models of Business Cycles, Basil-Blackwell, New York.

Mendoza, Enrique G. (1995), "The Terms of Trade, the Real Exchange Rate and Economic Fluctuations," International Economic Review, vol. 36, pp. 101-137.

(1996), "Terms-of-Trade Uncertainty and Economic Growth: Are Risk Indicators Significant in Growth Regressions," forthcoming, Journal of Development Economics.

Rebelo, Sergio and Carlos A. Végh, (1995), "Real Effects of Exchange-Rate-Based Stabilization: An Analysis of Competing Theories," NBER Macro Annual, National Bureau of Economic Research, Cambridge: MA. 
Reinhart Carmen M. and Carlos A. Végh (1994), "Inflation Stabilization in Chronic Inflation Countries: The Empirical Evidence," mimeo, Research Department, International Monetary Fund.

(1995), "Nominal Interest Rates, Consumption Booms, and Lack of Credibility: A Quantitative Examination," Journal of Development Economics, forthcoming.

Rodriguez, Carlos A. (1982), "The Argentine Stabilization Plan of December 20th," World Development. vol. 10, pp. 801-811.

Roldós, Jorge (1995), "Supply-Side of Disinflation Programs," IMF Staff Papers, vol 42., pp. 158-183.

Schmitt-Grohe, Stephanie, (1995) "The International Transmission of Economic Fluctuations: Effects of U.S. Business Cycles on the Canadian Economy," Finance and Economics Discussion Series, No. 95-6, Board of Governors of the Federal Reserve System, Washington D.C. 20551.

Uribe, Martin (1995), "Exchange-Rate-Based Inflation Stabilization: the Initial Real Effects of Credible Plans," IFDP No. 503, Board of Governors of the Federal Reserve System, Washington D.C.

(1996), "Comparing the Welfare Costs and the Initial Dynamics of Altemative Temporary Stabilization Policies," IFDP No. 539, Board of Governors of the Federal Reserve System, Washington DC.

Végh, Carlos A. (1992), "Stopping High Inflation: An Analytical Overview," IMF Staff Papers, vol. 39, pp. 626-695. 

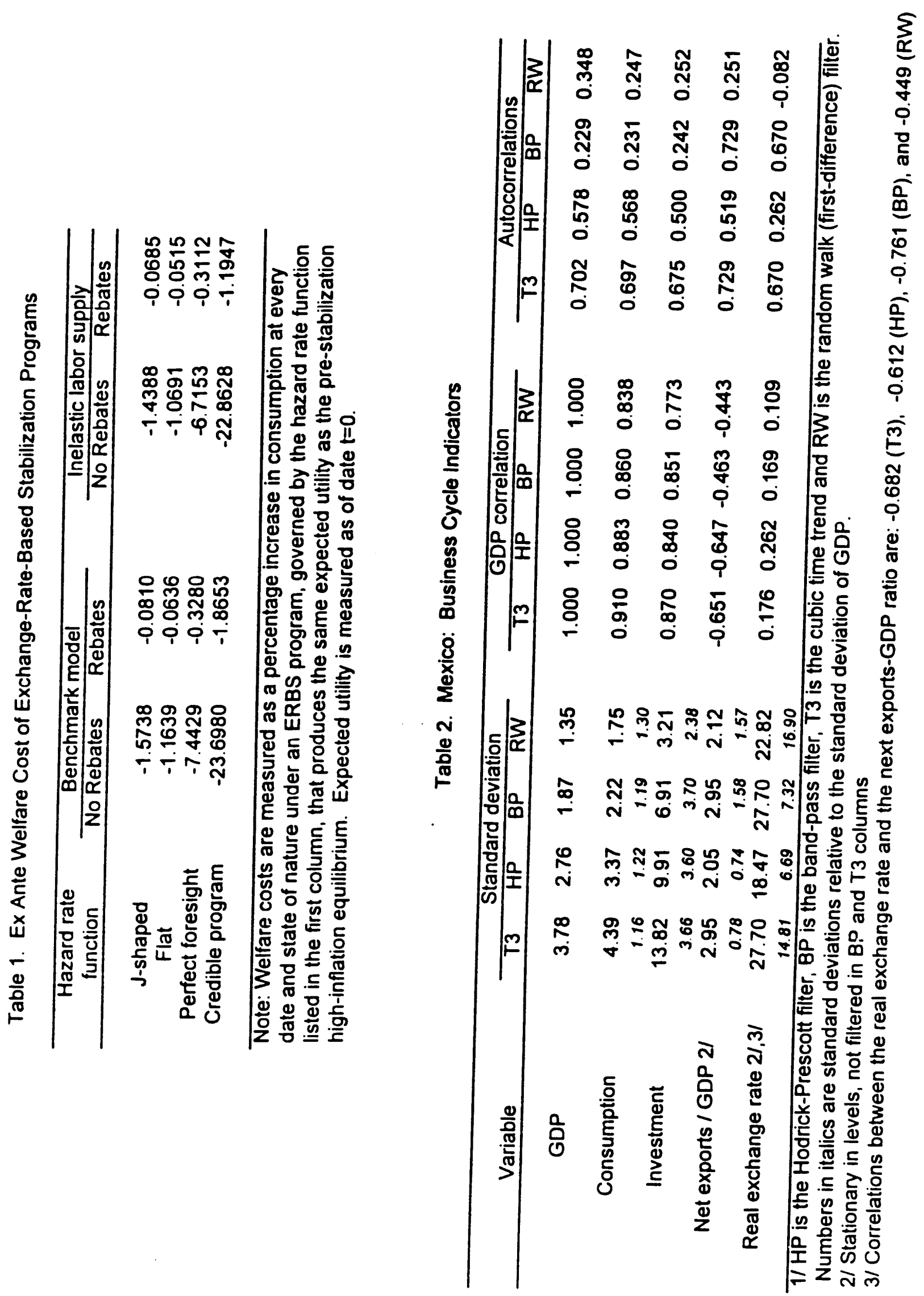
$-38-$

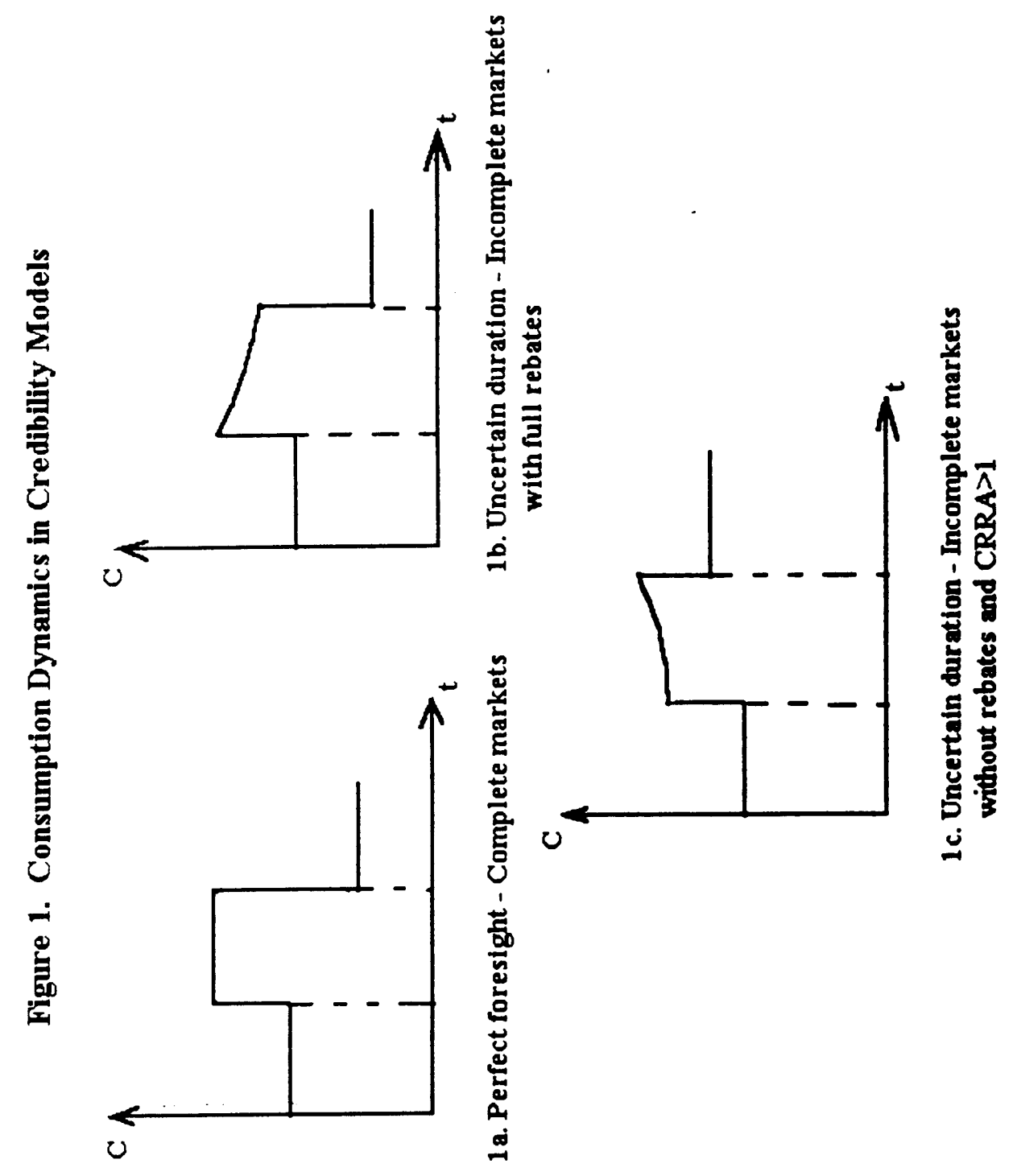


Figure 2: HAZARD FUNCTIONS

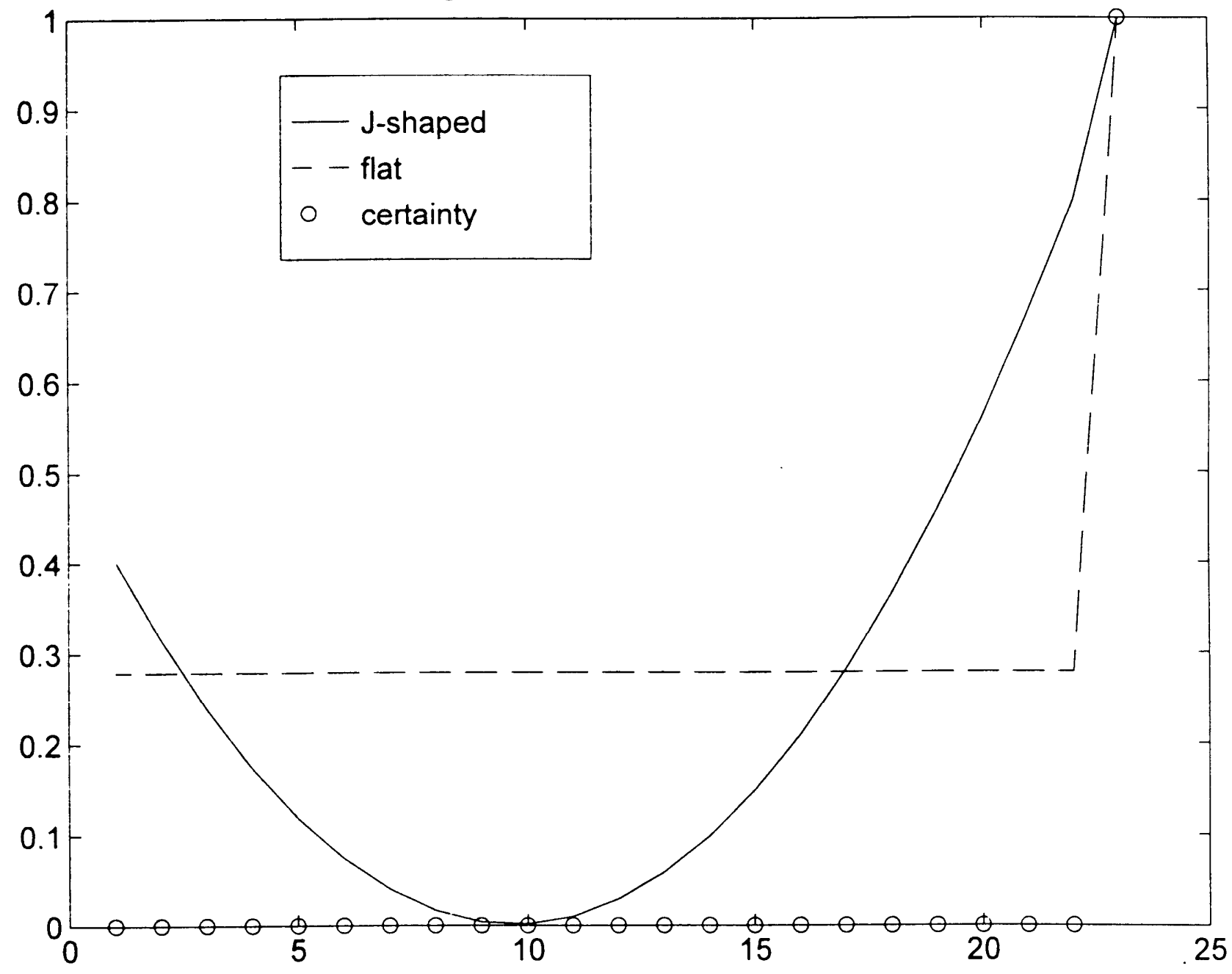


Figure 3: CONSUMPTION DYNAMICS UNDER A TEMPORARY TARIFF CUT (endowment economy case)

\section{Perfect foresight}

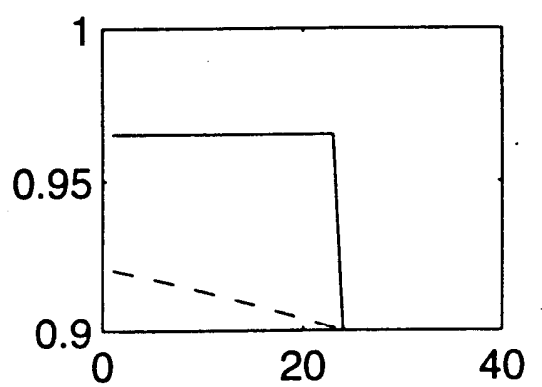

Rebate and $\sigma=2.61$

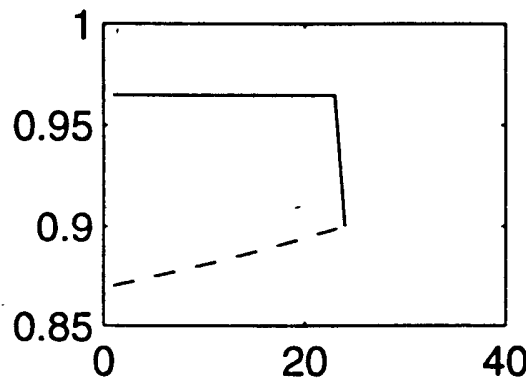

No rebate and $\sigma=2.61$

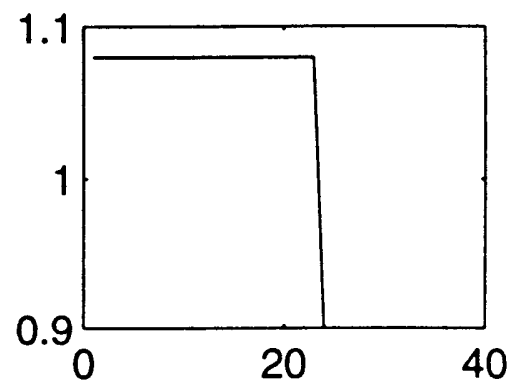

No rebate and $\sigma=1$

Uncertain Duration: flat hazard function

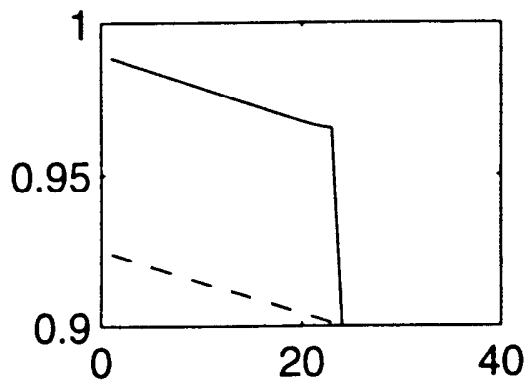

Rebate and $\sigma=2.61$

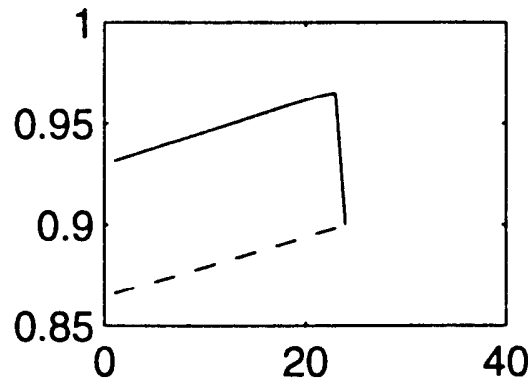

No rebate and $\sigma=2.61$

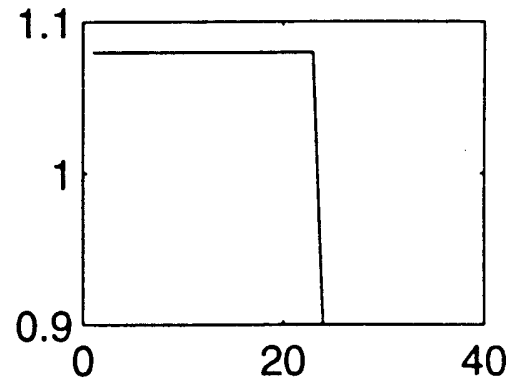

No rebate and $\sigma=1$

Uncertain Duration: non-linear hazard rate

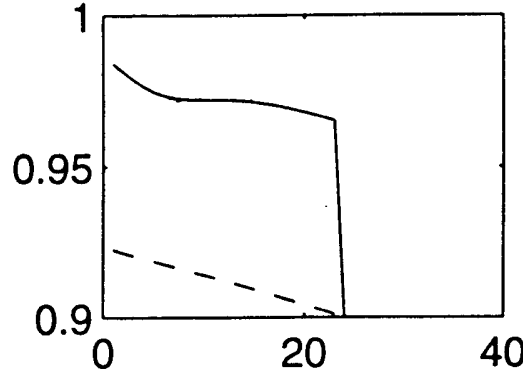

rebate and $\sigma=2.61$

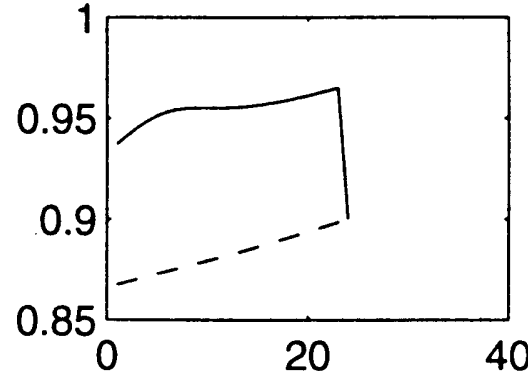

No rebate and $\sigma=2.61$

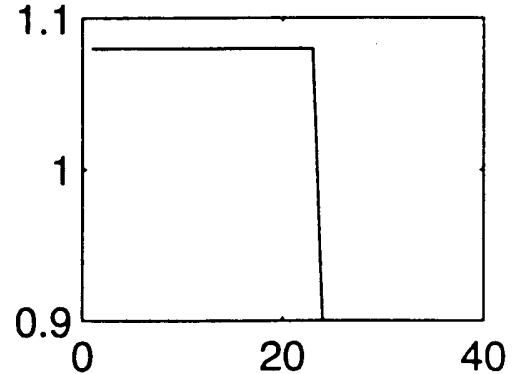

No rebate and $\sigma=1$ before the policy switch _... at and after the policy switch 
Figure 4: MACROECONOMIC DYNAMICS OF AN EXCHANGE-RATE BASED STABILIZATION OF UNCERTAIN DURATION*
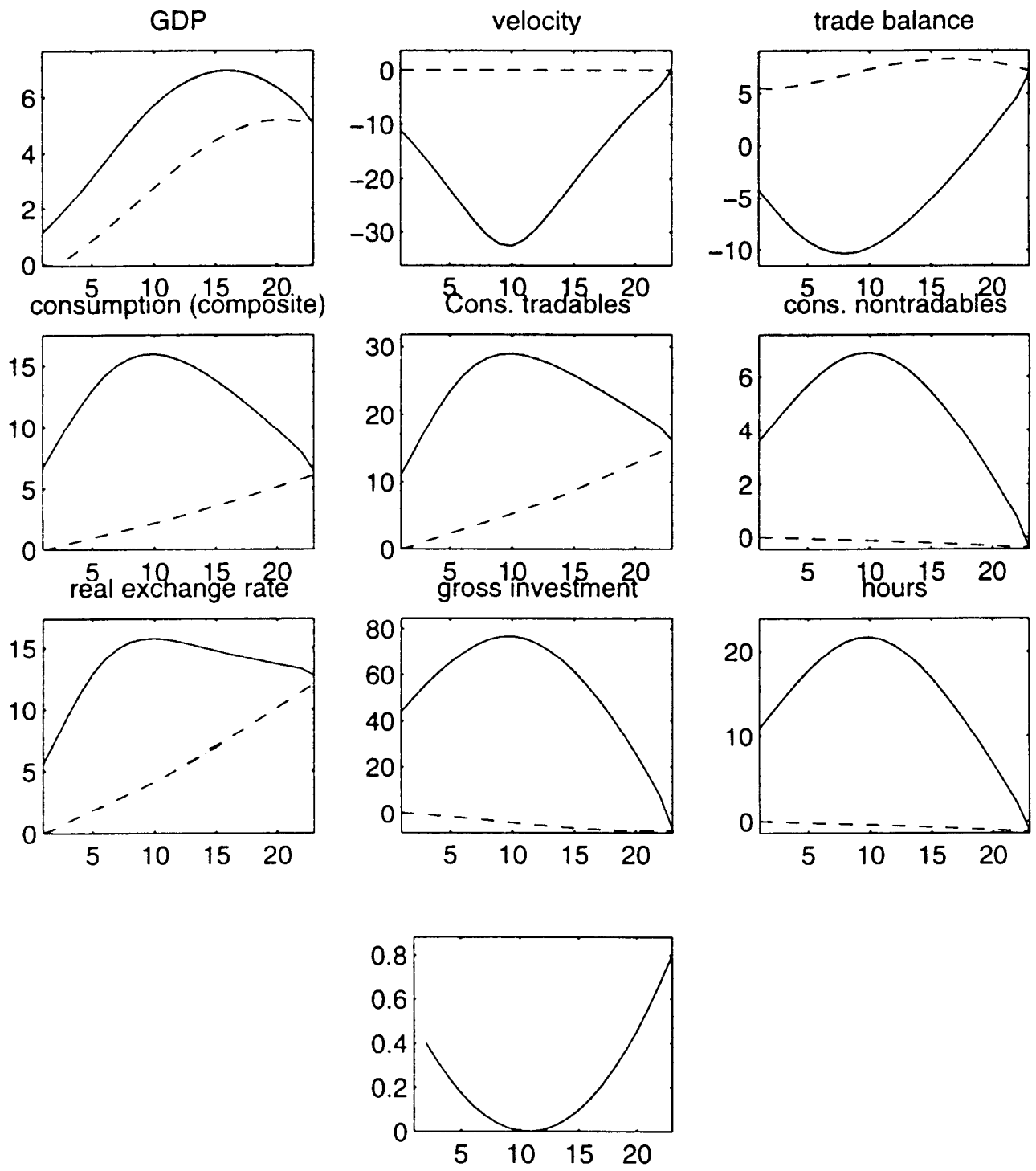

hazard function

* All variables, except $N X_{t} / Y_{t}$, are expressed in percentage deviations from their pre-stabilization steadystate. Solid lines denote pre-collapse values and broken lines at-collapse values. 
Figure 5: SENSITIVITY ANALYSIS*

The Benchmark Model
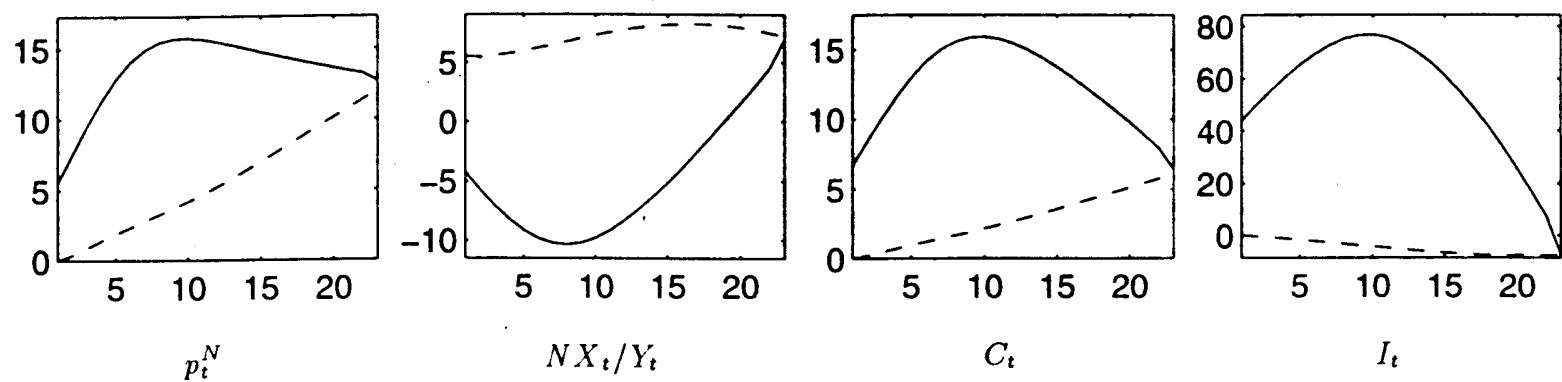

Flat Hazard Rate
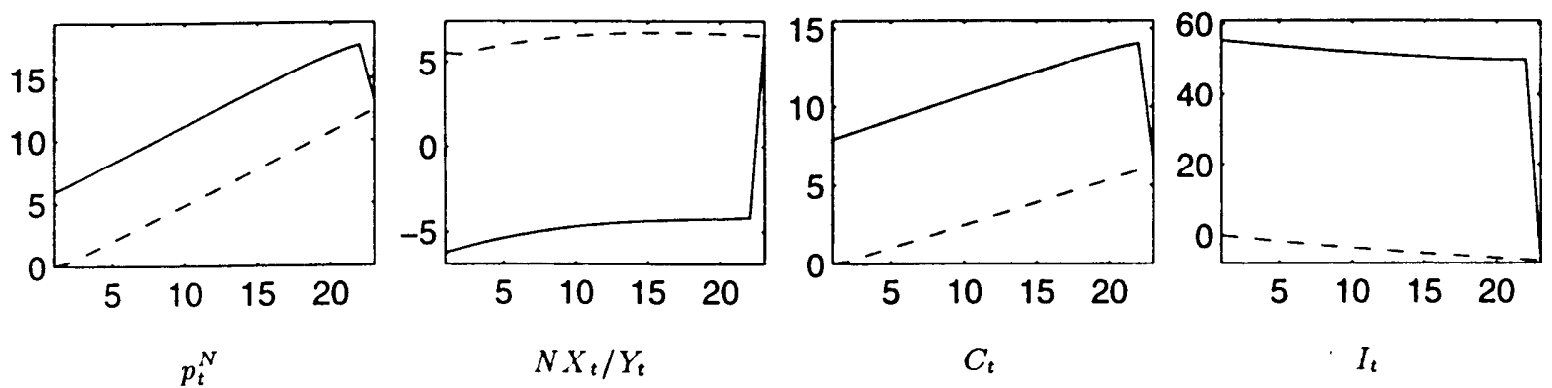

Perfect Foresight
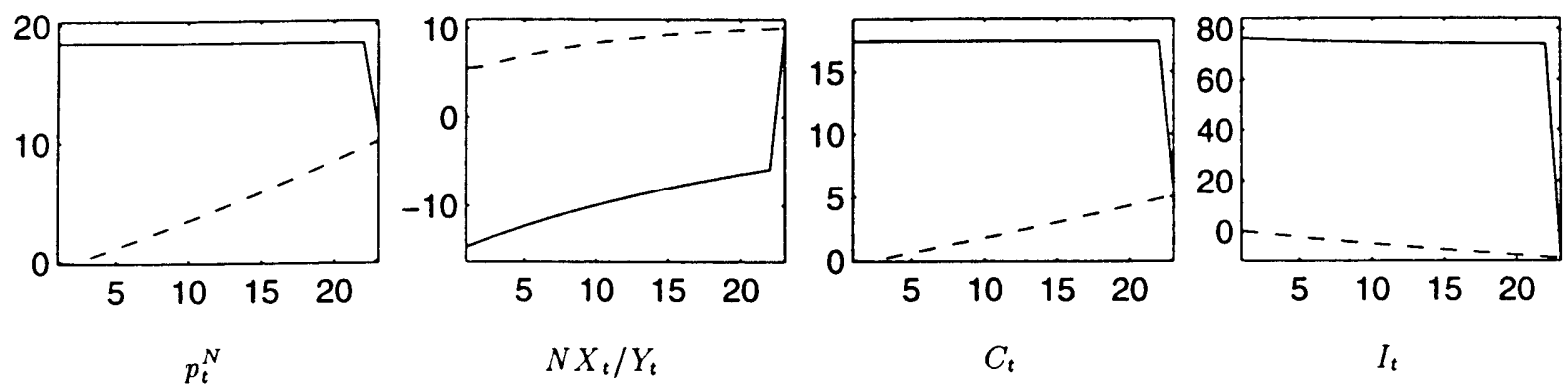

Full Rebate $\left(\eta_{s}=\eta_{m}=1\right)$
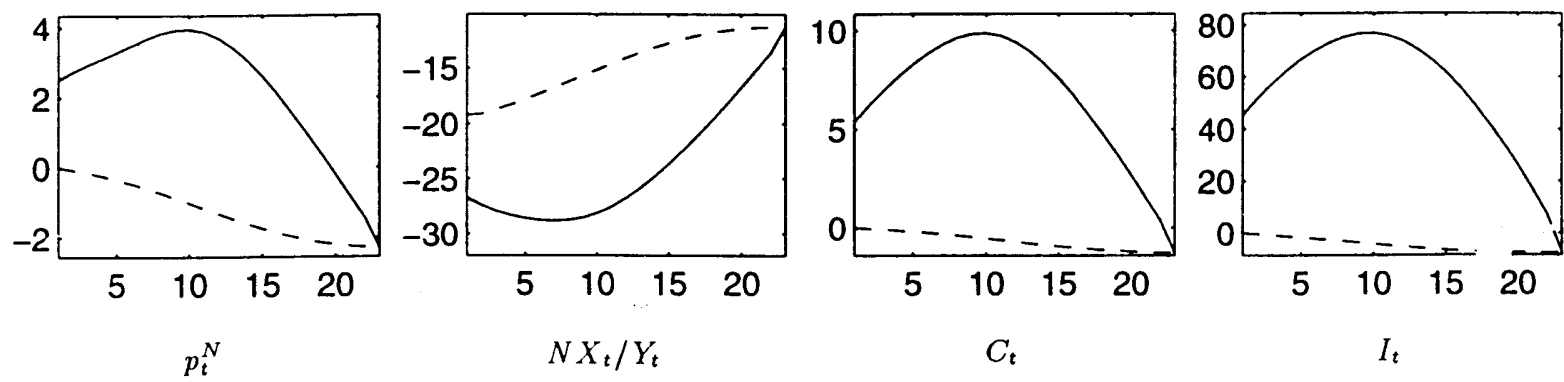

* All variables, except $N X_{t} / Y_{t}$, are expressed in percentage deviations from their pre-stabilization steadystate. Solid lines denote pre-collapse values and broken lines at-collapse values. 
Figure 5: (continued) SENSITIVITY ANALYSIS

Inelastic Labor Supply $(\rho=0)$
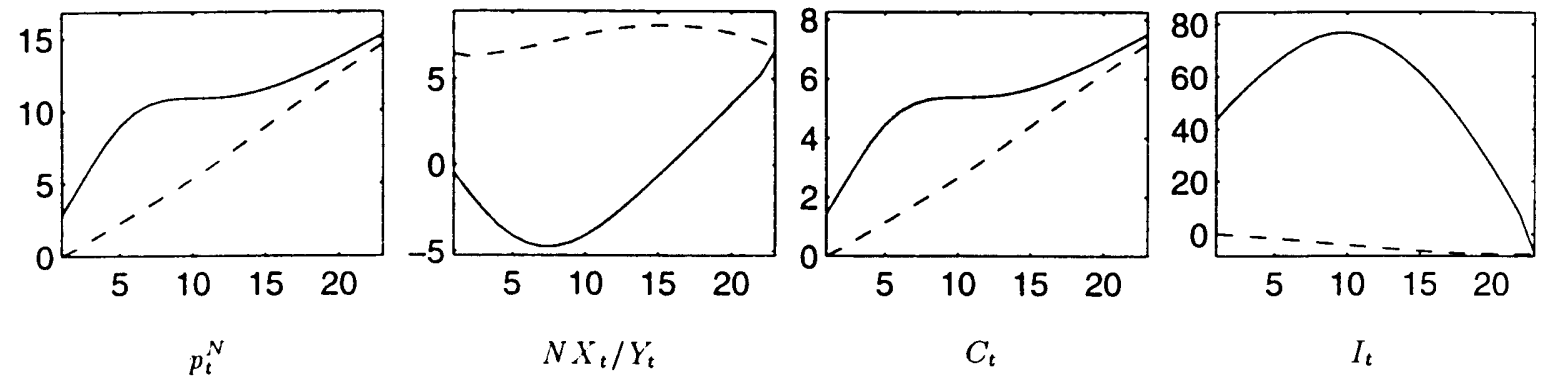

Low Intertemporal Elasticity of Substitution $(\sigma=5)$
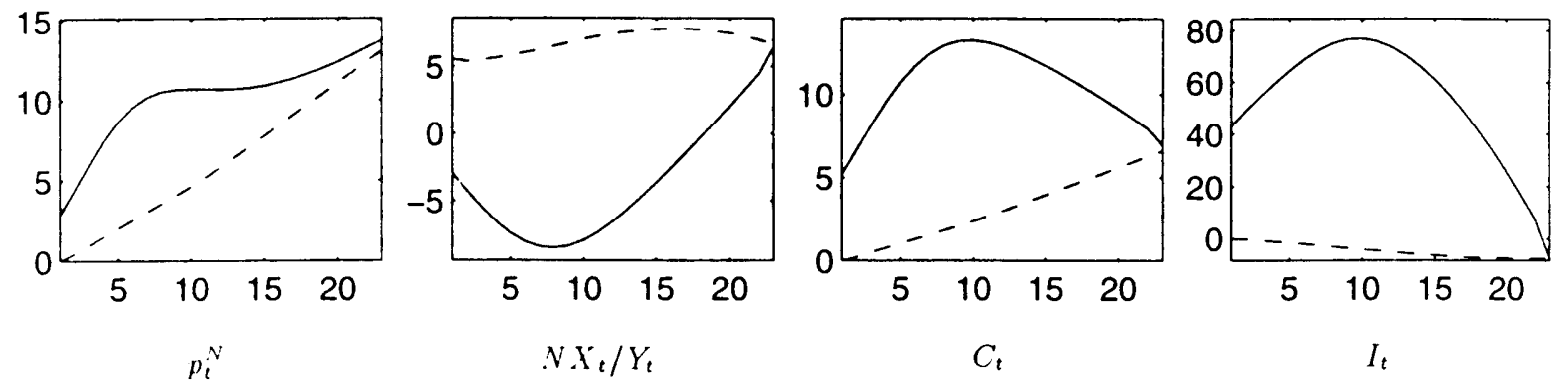

Cobb-Douglas Aggregator Function $(\mu=0)$
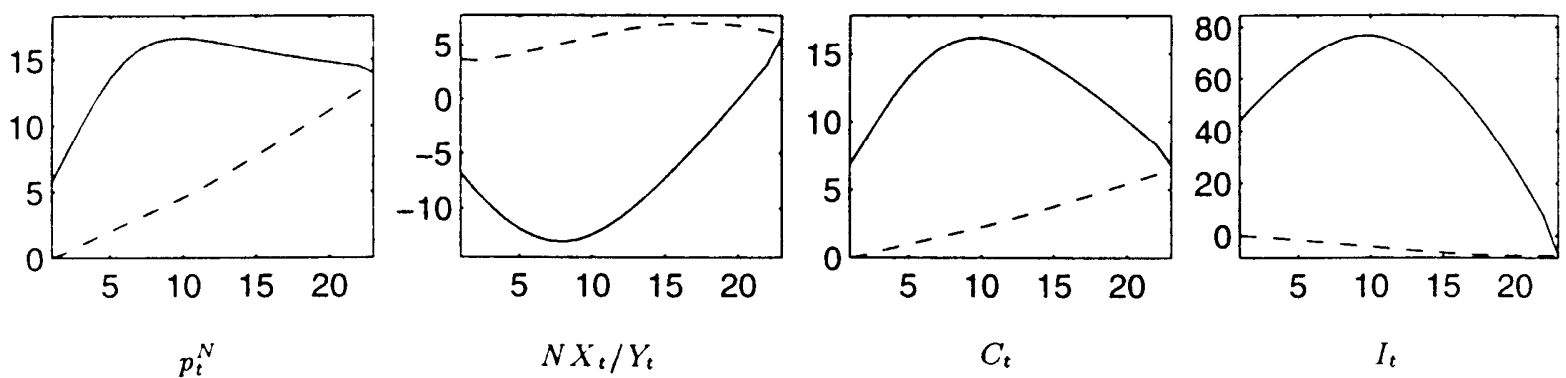

Extended Time Horizon $(J=36)$
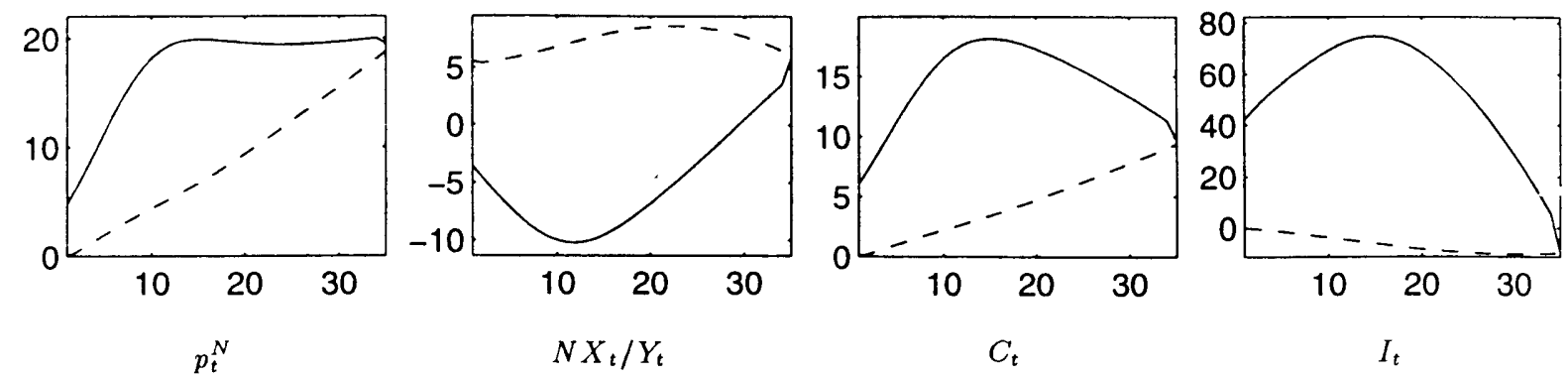
Figure 5: (continued) SENSITIVITY ANALYSIS

High Steady State Money Velocity $\left(\mathrm{r}^{H}=15.4\right.$ per vear)
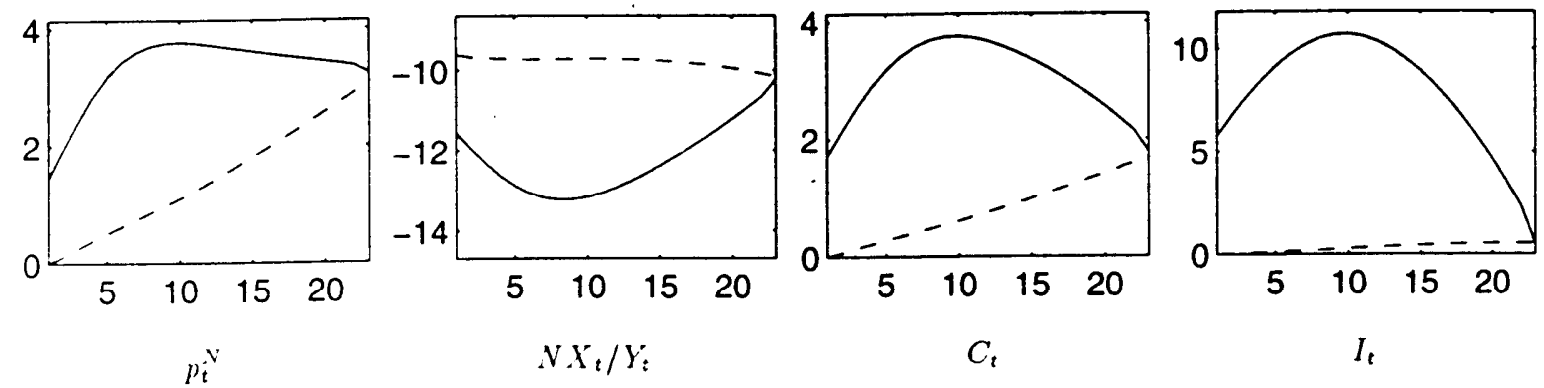

Non-zero Probability of Long-Run Success

$\operatorname{Pr}\left(\epsilon_{J}=e^{H} \mid \epsilon_{J-1}=\epsilon^{L}\right)=.9$ and $\operatorname{Pr}\left(e_{J+j}=e^{i} \mid e_{J}=e^{i}\right)=1$ for $i=H, L$ and $j>1$
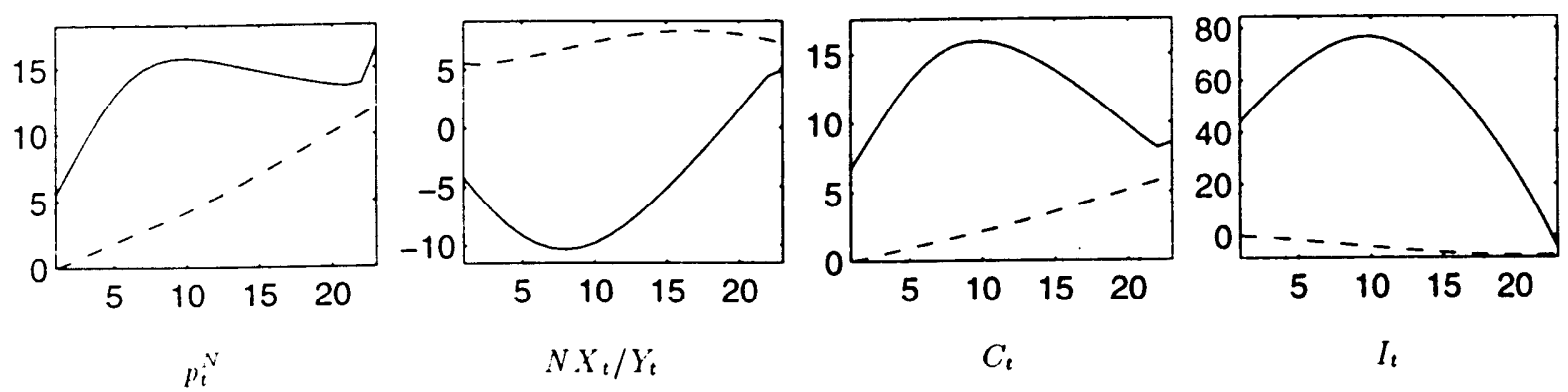

$$
\operatorname{Pr}\left(\epsilon_{J}=e^{H} \mid e_{J-1}=e^{L}\right)=.5 \text { and } \operatorname{Pr}\left(e_{J+j}=e^{i} \mid e_{J}=e^{i}\right)=1 \text { for } i=H, L \text { and } j>1
$$
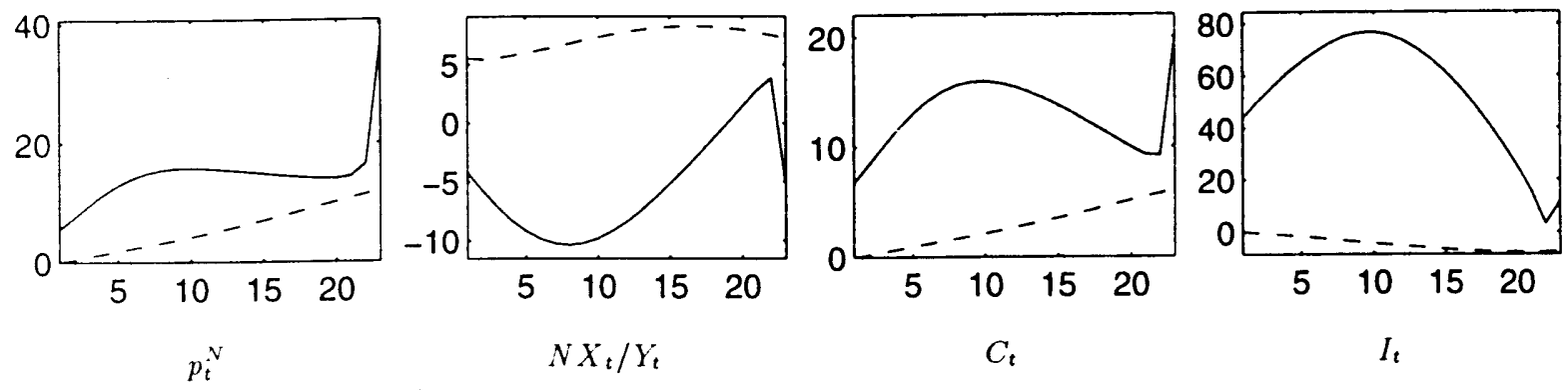
Figure 6: Ex-Post Welfare Costs of ERBS Programs

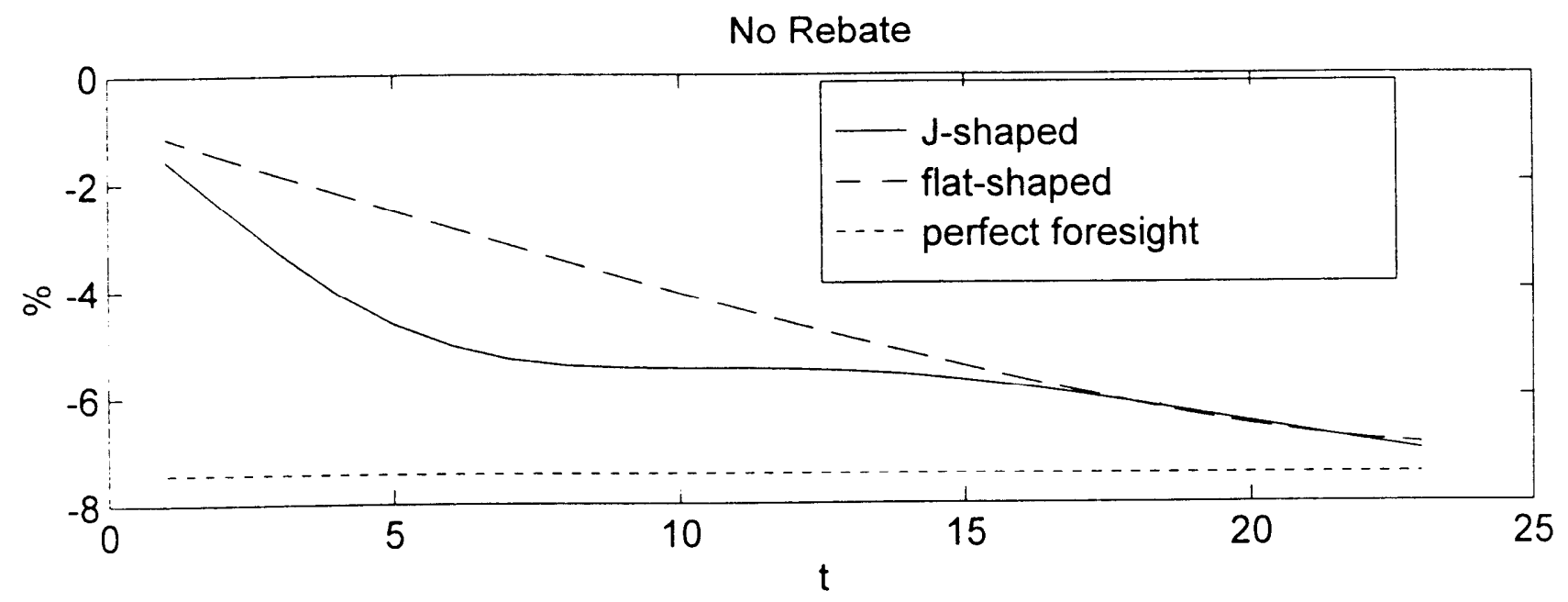

Full Rebate

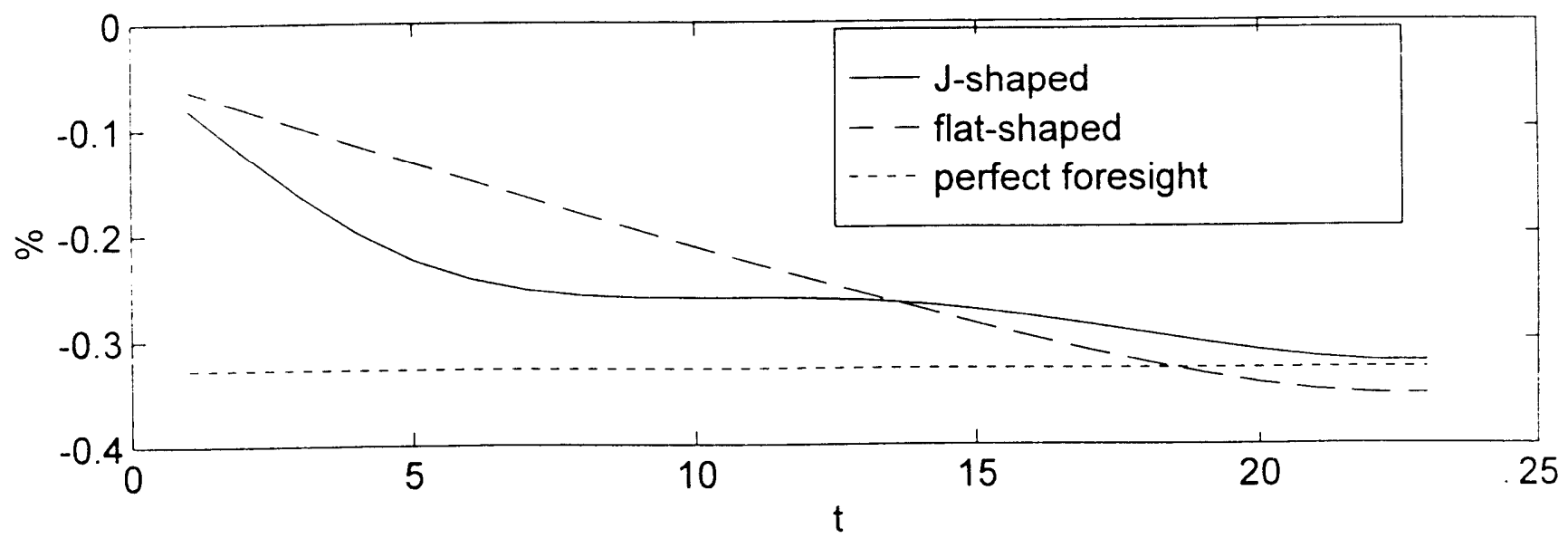


Figure 7:

Consumption and Labor Supply Allocations Under Alternative Hazard Rates NO REBATE
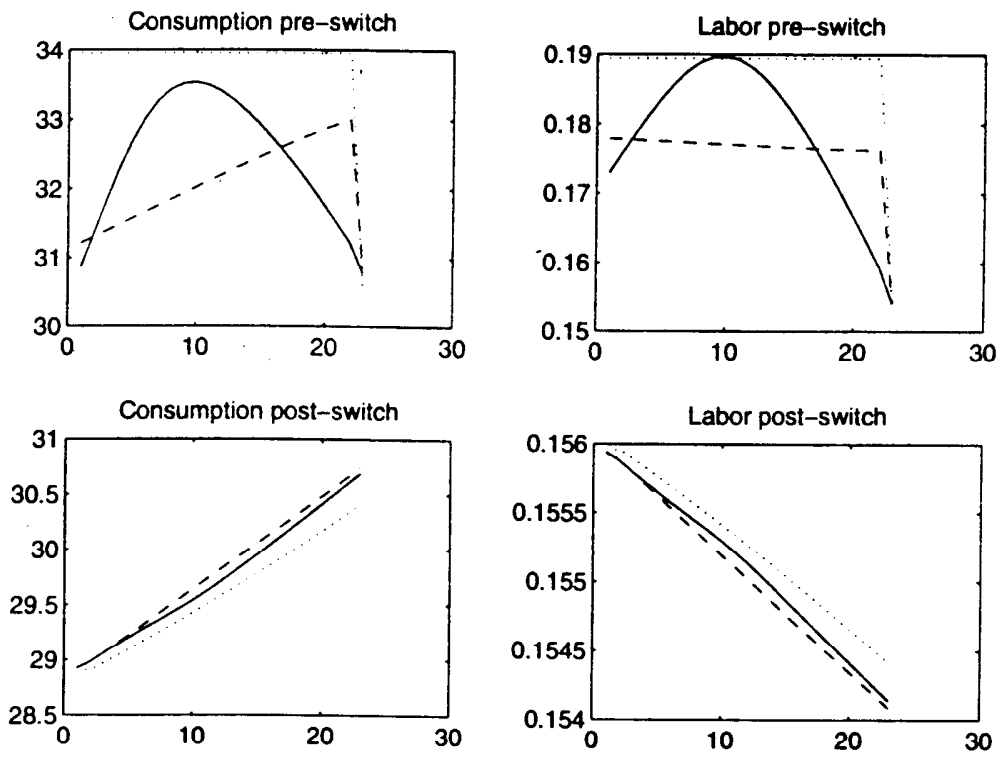

\section{FULL REBATE}
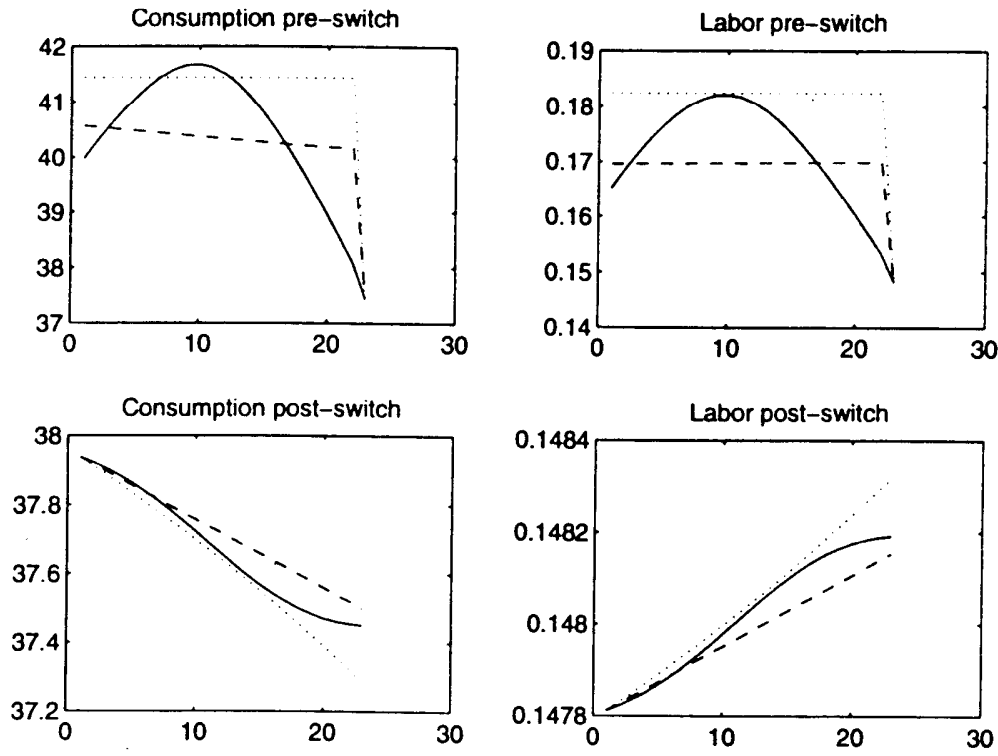

J-shaped _. . - flat ...perfect foresight 
Figure 8

Mexico: Real and Nominal Exchange Rates

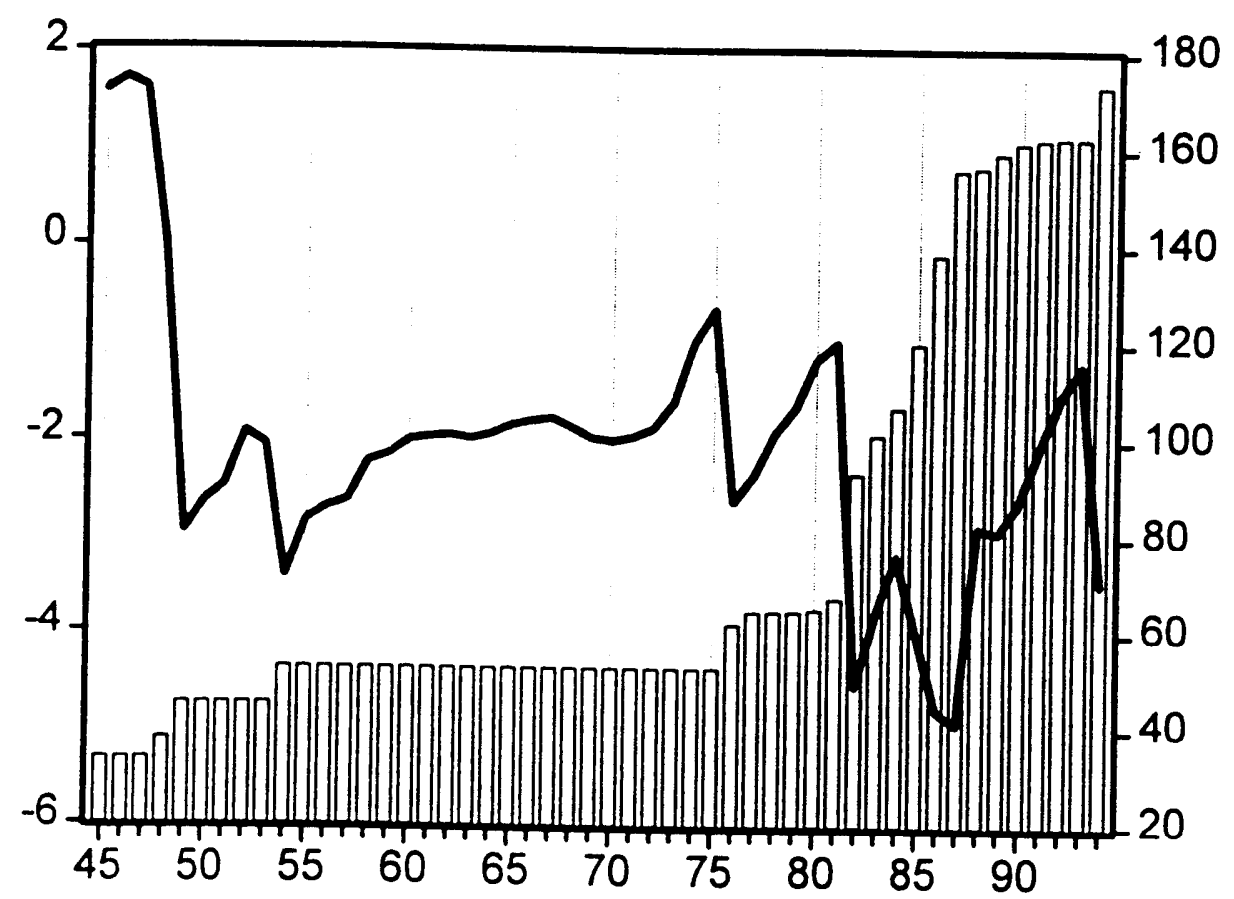

log nominal exchange rate real exchange rate index (left scale) (right scale)

Note: The real exchange rate index is $P / E P^{*}$, where $P$ is the Mexican CPI, $E$ is the nominal exchange rate in nuevos pesos per dollar, and $P^{\star}$ is the U.S. CPI. The base of the index is $1970=100$.

Figure 9

Mexico: GDP Per capita and Trend Estimates

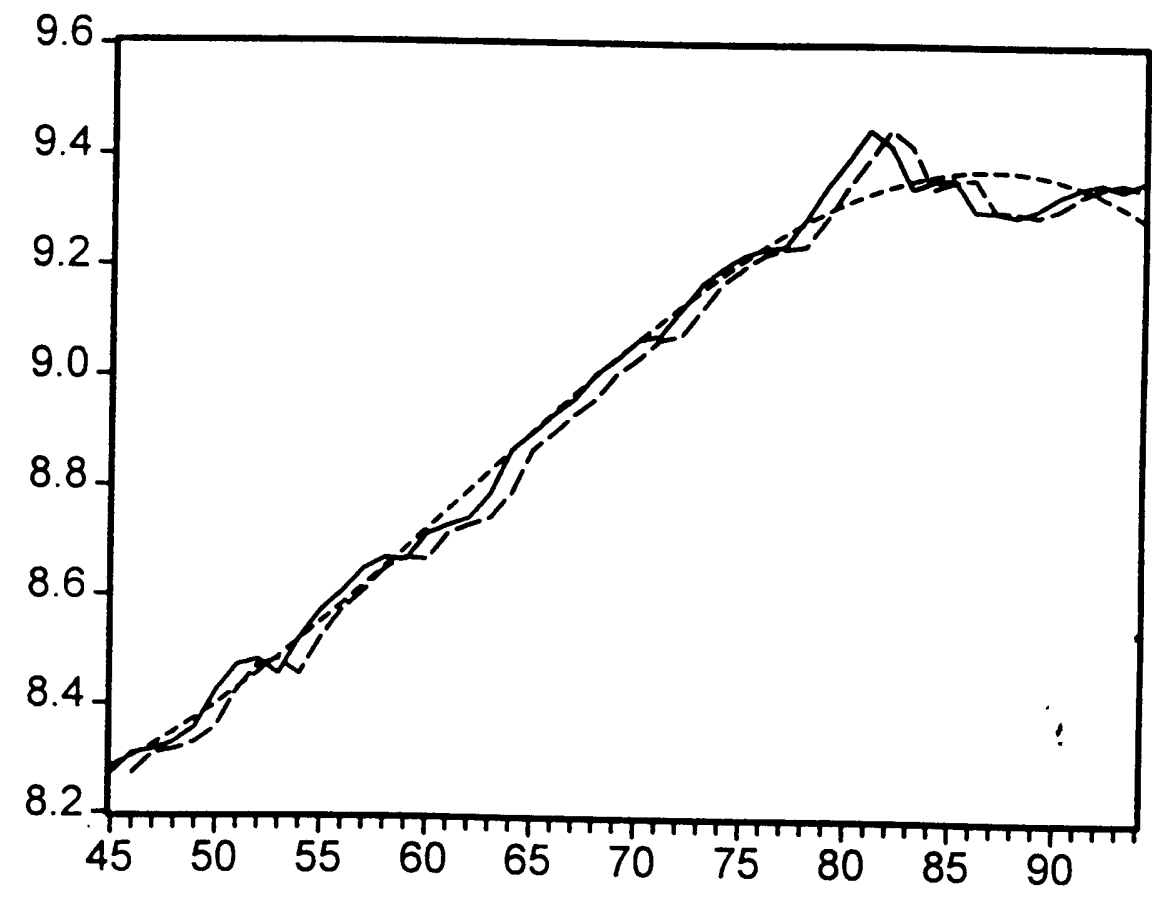


Figure 10

Post-war Mexican Business Cycles

Fixed capital formation

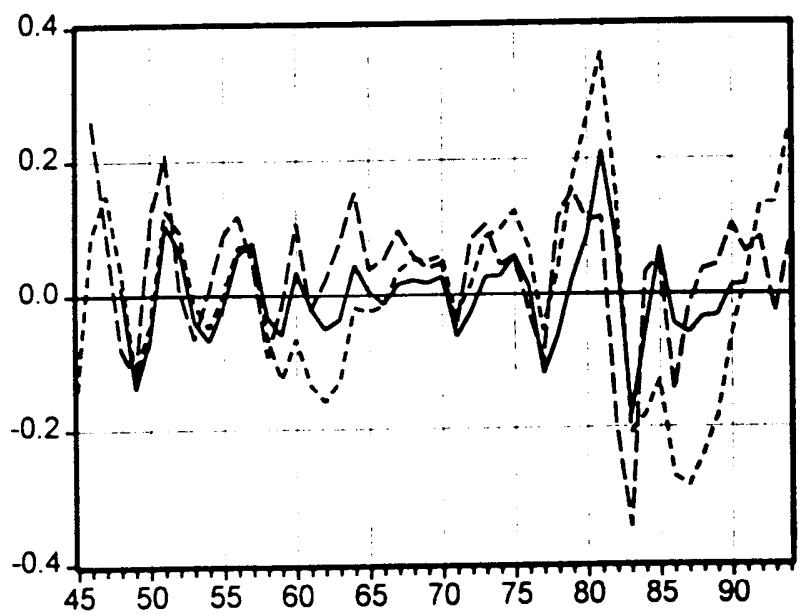

Gross domestic product

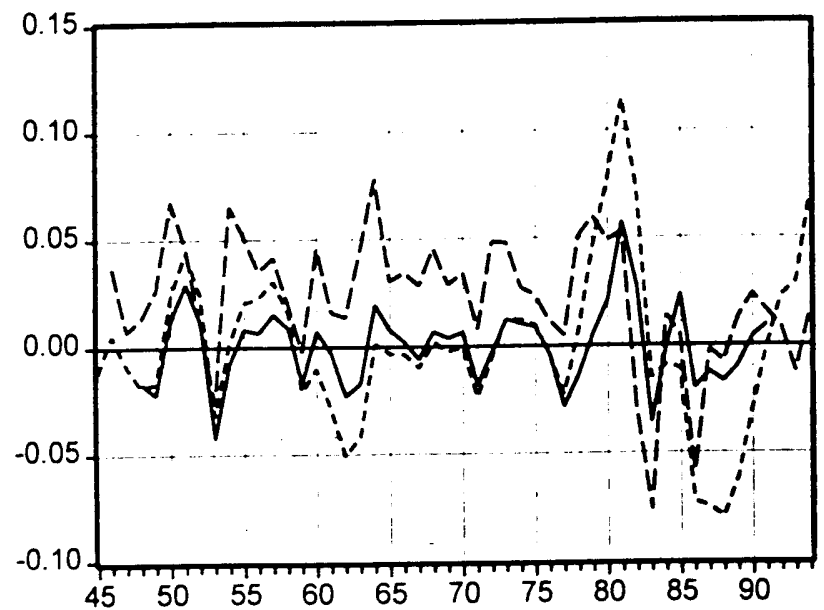

band-pass filter -..-- cubic trend filter - - - first-difference filter
Private consumption

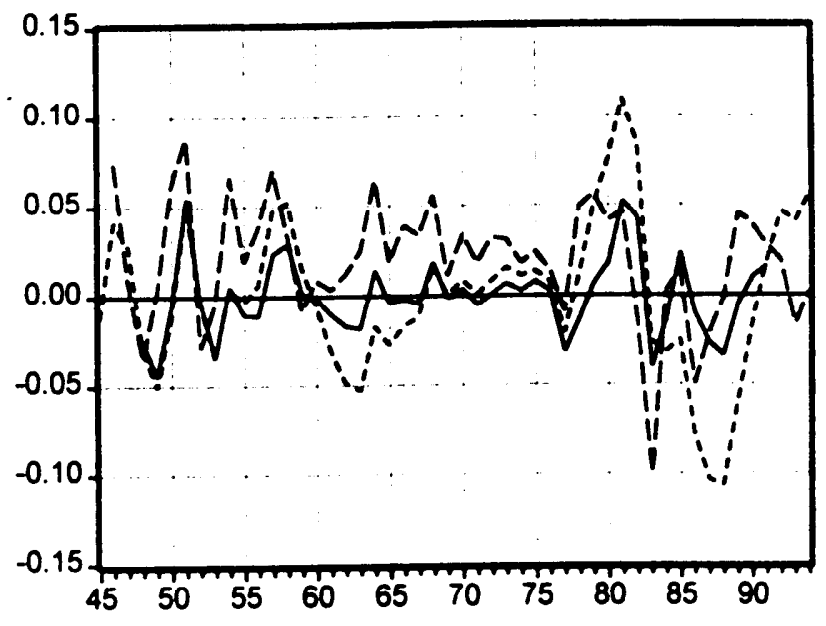

— band-pass filter ---- cubic trend filter - - - first-difference filter

Net exports / GDP ratio

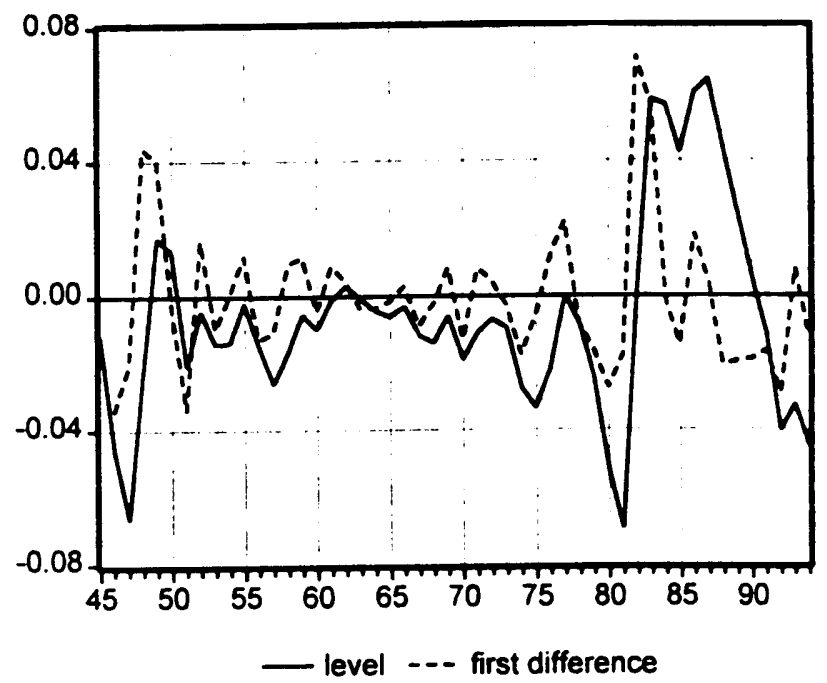


Figure 11

Mexican Business Cycles: 1983:1-1994:4

(percent deviations from quadratic trend, except RER)

GDP

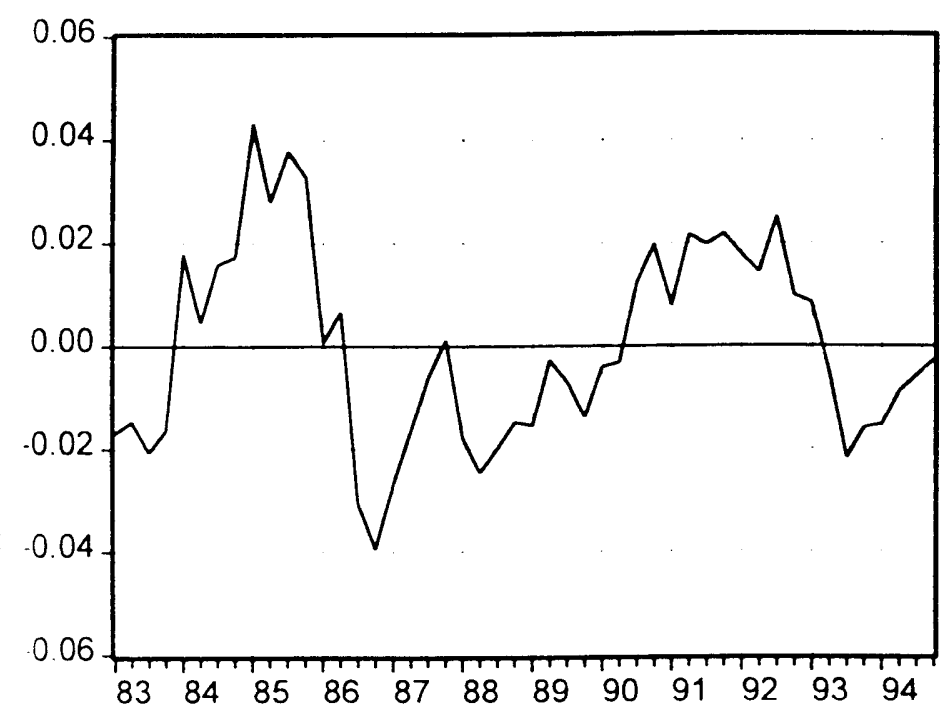

Private consumption

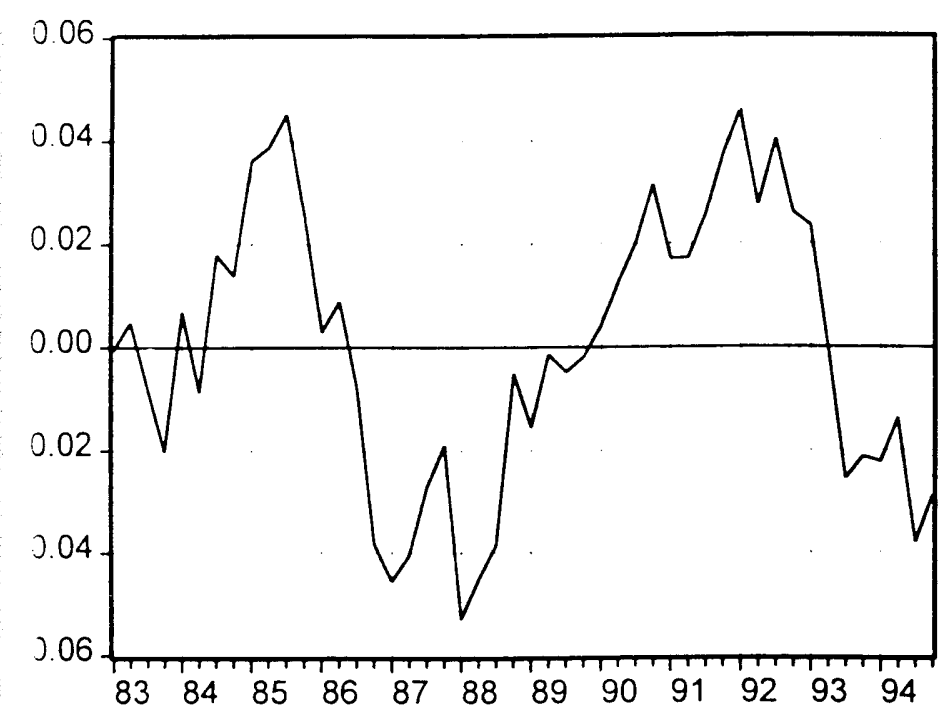

Investment

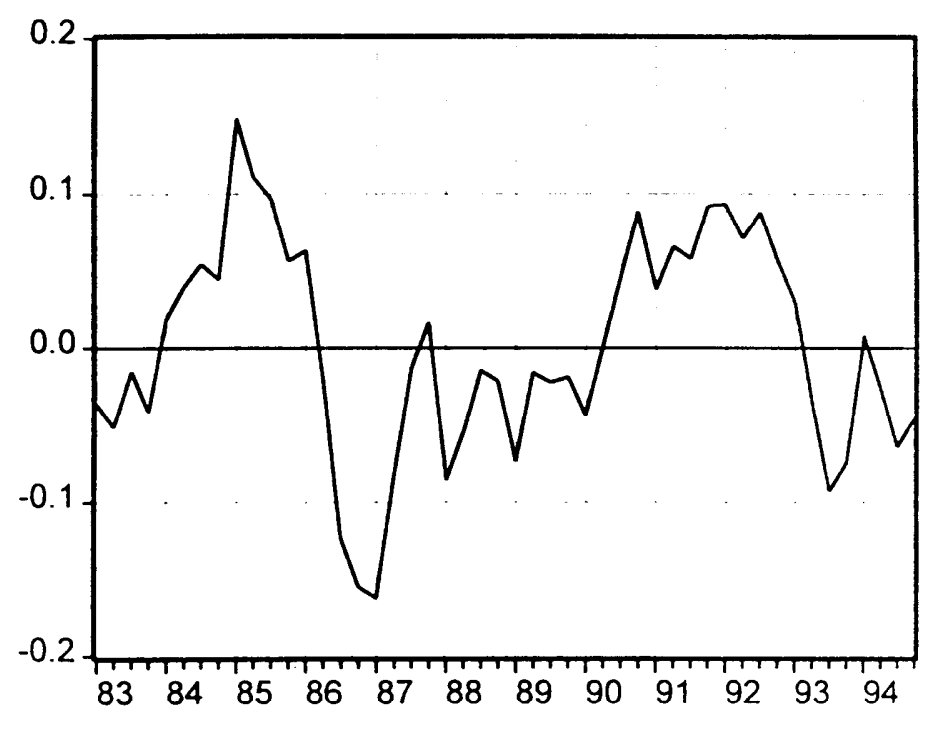

Real exchange rate

(log of real effective exchange rate, 1988:1=100)

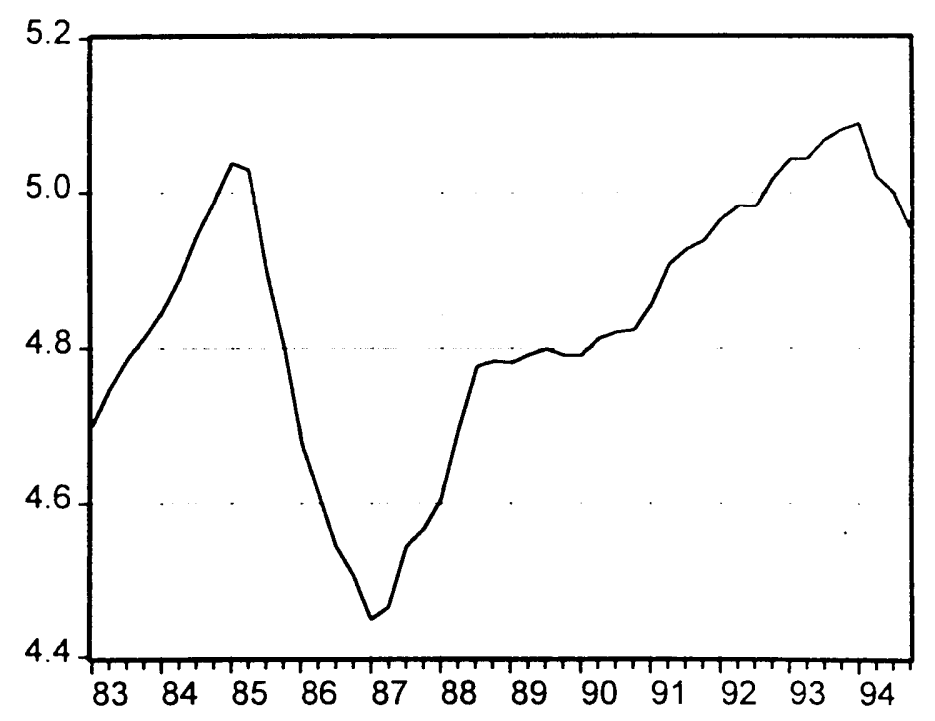




\section{Appendix: Solution Method}

Computing equilibrium dynamics for models of incomplete markets is a complex task in general because of difficulties involved in tracing the optimal state-contingent evolution of wealth. In the case of small open economy models, with perfect capital mobility and conventional utility functions, this problem is compounded by the fact that stationary equilibria, when they exist, are determined by initial conditions. In light of these difficuities. we developed an algorithm that obtains a nearexact solution for equilibrium dynamics.

The equilibrium stochastic processes that characterize macroeconomic dynamics are computed by backward recursion on the general equilibrium system defined by equations (5)-(12) and (14)(15). The method exploits the assumptions that (a) the date of collapse of the program is a random variable with finite support $([1, J])$ and (b) that the collapse of the program is an absorbent state. Thus, there is a distant future date in which policy uncertainty is resolved. This imposes welldefined terminal conditions on consumption, leisure and money velocity, all of which jump to their corresponding high-inflation stationary equilibria on the date of the collapse. The current account and investment take some time to reach their steady state equilibria because of the inertia induced by capital adjustment costs, but their post-collapse dynamics are easily determined by solving a linearized version of the Euler equation for capital accumulation.

The algorithm begins by guessing period- $J$ values for the state variables (capital and bonds) and uses intertemporal Euler equations and the budget constraint to compute the values taken by these variables in periods $t=J-1, J-2, \ldots 0$. Solutions for the control and co-state variables are provided by atemporal optinality and market-clearing conditions. A shooting algorithm is then introduced to ensure that the period-J guess is consistent with the initial conditions for the capital stock and hond holdings.

Notation: let $x_{t}^{H}$ denote the value assumed by $x_{t}$ if $e_{t}=e^{H}$ and $e_{t-1}=e^{L}$, and $x_{t}^{L}$ the value assumed by $x_{t}$ if $\epsilon_{t}=e^{L}$. The exception to this notation is the capital stock, $K_{t+1}^{T} . K_{t+1}^{T H}$ denotes the value assumed by $K_{t+1}^{T}$ if $e_{t}=e^{H}$ and $e_{t-1}=e^{L}$, and $K_{t+1}^{L}$ the value assumed by $K_{t+1}^{T}$ if $e_{i}=f^{L}$.

Initial conditions are given for the capital stock, $K_{0}^{T}$, the stock of real financial wealth. $B_{-1}+$ $m_{-1} /\left(1+e_{0}\right)$. Since $\epsilon_{t}=e^{H}$ is an absorbent state, it follows from the equiibrium conditions that in this event consumption and money velocity are constant. In particular money velocity solves 1 - $S^{\prime}\left(V^{H}\right) V^{H^{2}}=\beta /\left(1+e^{H}\right)$ (see equation (11)). Given this value for money velocity, it follows from (12) that $K_{t+j}^{T}, j \geq 1$ follows a second order differential equation with a unique steady state. $h^{-T}$, given by $\left(1-\alpha_{T}\right)\left(K^{T} / L^{T}\right)^{-\alpha_{T}}=(r+\delta)\left(1+S\left(V^{H}\right)+S^{\prime}\left(V^{H}\right) V^{H}\right)$.

Equilibrium dynamics are computed in the following way. Start with an initial guess for $K_{J-1}^{T L}$. $C_{J-1}^{T L}$ and $\left\{m_{t-1}^{L}\right\}_{t=0}^{J-1}$ - this last guess is necessary only if the government does not fully rebate seignorage income $\left(\eta_{m}<1\right)$.

(1) Period $J-1$ : In this period all variables except $K^{-T}$ reach their steady state. since the exchange rate uncertainty is removed.

(1.1) Given $C_{J-1}^{T L}$, find $C_{J-1}^{N L}, p_{J-1}^{N L}, L_{J-1}^{N L}$ and $\lambda_{J-1}^{L}$ by solving the intra-tenporai Fuler or tions (7)-(9) and the market clearing condition (13).

(1.2) Compute an approximate solution for $\Lambda_{J-1+j}^{-T}, j>1$ by solving a lincarized version of (12). 
(1.3) Find $B_{J_{-2}}^{L}$ by solving (14) forward, using $m_{J-2}^{L}$ and (5)-(6) to eliminate $G_{J-1}$ and $T_{J-1}$.

(1.4) Use $B_{J-2}^{L}$ and $m_{J-2}^{L}$ to solve equations (5)-(9) and (13)-(14) for $C_{J-1}^{T H}, C_{J-1}^{N H}, p_{J-1}^{N H}, L_{J-1}^{N H}$ $\lambda_{J-1}^{H} . G_{J-1}^{H}$ and $T_{J-1}^{H}$.

(2) Periods $t=J-2, \ldots 0$

(2.1) Given $V_{t+1}^{i}, \lambda_{t+1}^{i}, i=L, H, K_{t+j}^{T L}, j=1,2$, and $K_{t+2}^{T H}$, solve the intertemporal Euler equations (10)-(12) for $V_{t}^{L}, \lambda_{t}^{L}$, and $K_{t}^{T L}$.

(2.2) Given $V_{t}^{L}$ and $\lambda_{t}^{L}$, solve (7)-(9) and (13) for $C_{t}^{T L}, C_{t}^{N L}, p_{t}^{N L}$, and $L_{t}^{N L}$. $T_{t}^{L}$.

(2.3) Use $B_{t}^{L}, m_{t-1}^{L}$ and the values obtained in (2.2) to solve (5)-(6) and (14) for $B_{t-1}^{L}, G_{t}^{L}$ and

(2.4) $B_{t-1}^{L}$ and $m_{t-1}^{L}$ can then be used to solve (7)-(9), (13) and (14) (forward) for $\lambda_{t}^{H}, C_{t}^{T H}$, $C_{t}^{N H}, p_{t}^{N H}$, and $L_{t}^{N H}$.

(2.5) Use a linearized version of (12) to solve for $K_{t+1}^{T H}$.

(3) Steps (1)-(2) yield a new vector of real balances $\left\{m_{t-1}^{L}\right\}_{t=0}^{J-1}=\left\{\left(C_{t-1}^{T L}+p_{t-1}^{N L} C_{t-1}^{N L}\right) V_{t-1}^{L}\right\}_{t=0}^{J-1}$. If this vector differs from the one guessed, use it as the new guess and repeat steps (1)-(2).

(4) If $K_{0}^{T}$ differs from the desired initial condition for the capital stock, change the guess for $K_{J-1}^{T L}$ and repeat steps (1)-(3). ( $K_{0}^{T}$ is increasing in $K_{J-1}^{T L}$.)

(5) If $B_{-1}+m_{-1} /\left(1+\epsilon_{0}\right)$ differs from the desired initial condition for the stock of financial wealth. change the gisess for $C_{J-1}^{T L}$ and repeat steps (1)-(4). $\left(B_{-1}+m_{-1} /\left(1+e_{0}\right)\right.$ is increasing in $\left(C_{J-1}^{T L} \cdot\right)$ 


\section{International Finance Discussion Papers}

IFDP

Number

The Syndrome of Exchange-Rate-Based Stabilizationn and the Uncertain Duration of Currency Pegs

547 German Unification: What Have We Learned from Milti-Country Models?

546 Returns to Scale in U.S. Production: Estimates and Implications

545 Mexico's Balance-of-Payments Crisis: A Chronicle of Death Foretold

544 The Twin Crises: The Causes of Banking and Balance-of-Payments Problems

543 High Real Interest Rates in the Aftermath of Disinflation: Is it a Lack of Credibility?

542 Precautionary Portfolio Behavior from a Life-Cycle Perspective

541 Using Options Prices to Infer PDF's for Asset Prices: An Application to Oil Prices During the Gulf Crisis

540 Monetary Policy in the End-Game to Exchange-Rate Based Stabilizations: The Case of Mexico

539 Comparing the Welfare Costs and the Initial Dynamics of Alternative Temporary Stabilization Policies

538 Long Memory in Inflation Expectations: Evidence from International Financial Markets

\section{Using Measures of Expectations to Identify the} Effects of a Monetary Policy Shock

Regime Switching in the Dynamic Relationship between the Federal Funds Rate and Innovations in Nonborrowed Reserves
Enrique G. Mendoza

Martin Uribe

Joseph E. Gagnon

Paul R. Masson

Warwick J. McKibbin

Susanto Basu

John G. Fernald

Guillermo A. Calvo

Enrique G. Mendoza

Graciela L. Kaminsky

Carmen M. Reinhart

Graciela L. Kaminsky

Leonardo Leiderman

Carol C. Bertaut

Michael Haliassos

William R. Melick

Charles P. Thomas

Steven B. Kamin

John H. Rogers

Martin Uribe

Joseph E. Gagnon

Allan D. Brunner

Chan Huh

Please address requests for copies to International Finance Discussion Papers, Division of International Finance, Stop 24, Board of Governors of the Federal Reserve System, Washington, D.C. 20551. 


\section{International Finance Discussion Papers}

IFDP

Number
Titles

1996

535

534

Regional Patterns in the Law of One Price:

The Roles of Geography vs. Currencies

\section{5}

532 Aggregate Productivity and the Productivity of Aggregates

531 A Century of Trade Elasticities for Canada, Japan, and the United States

$530 \quad$ Modelling Inflation in Australia

529

528

526 Uncertainty, Instrument Choice, and the Uniqueness

525 Targeting Inflation in the 1990s: Recent Challenges of Nash Equilibrium: Microeconomic and Macroeconomic Examples

Hyperinflation and Stabilisation: Cagan Revisited

On the Inverse of the Covariance Matrix in Portfolio Analysis

Economic Development and Intergenerational Economic Mobility

Human Capital Accumulation, Fertility and Growth: A Re-Analysis

Excess Returns and Risk at the Long End of the Treasury Market: An EGARCH-M Approach The Money Transmission Mechanism in Mexico
Edwin M. Truman

Jeffrey A. Frankel Andrew K. Rose

Charles Engel John H. Rogers

Susanto Basu John G. Fernald

Jaime Marquez.

Gordon de Brouwer Neil R. Ericsson

Marcus Miller Lei Zhang

Guy V.G. Stevens

Dale W. Henderson Ning S. Zhu

Richard T. Freeman Jonathan L. Willis

Murat F. Iyigun

Murat F. Iyigun

Allan D. Brunner David P. Simon

Martina Copelman Alejandro M. Werner 